\title{
Metatranscriptomic and functional metagenomic analysis of methylphosphonate utilization by marine bacteria
}

\author{
Asunción Martínez ${ }^{1,2}$, Laure-Anne Ventouras ${ }^{1,2}$, Samuel T. Wilson ${ }^{2,3}$, David M. Karl ${ }^{2,3}$ and \\ Edward F. DeLong ${ }^{1,2 *}$ \\ ${ }^{1}$ Division of Biological Engineering, Department of Civil and Environmental Engineering, Massachusetts Institute of Technology, Cambridge, MA, USA \\ ${ }^{2}$ Center for Microbial Oceanography: Research and Education (C-MORE), University of Hawaii, Honolulu, HI, USA \\ ${ }^{3}$ Department of Oceanography, School of Ocean and Earth Science and Technology, University of Hawaii, Honolulu, HI, USA
}

Edited by:

Anton F. Post, Marine Biological

Laboratory, USA

Reviewed by:

David J. Scanlan, University of

Warwick, UK

George S. Bullerjahn, Bowling Green

State University, USA

John Quinn, Queen's University, UK

*Correspondence:

Edward F. DeLong, Division of

Biological Engineering, Department

Civil and Environmental Engineering,

Massachusetts Institute of

Technology, MIT48-427, 15 Vassar

St., Cambridge, MA 02139, USA

e-mail: delong@mit.edu
Aerobic degradation of methylphosphonate (MPn) by marine bacterioplankton has been hypothesized to contribute significantly to the ocean's methane supersaturation, yet little is known about MPn utilization by marine microbes. To identify the microbial taxa and metabolic functions associated with MPn-driven methane production we performed parallel metagenomic, metatranscriptomic, and functional screening of microcosm perturbation experiments using surface water collected in the North Pacific Subtropical Gyre. In nutrient amended microcosms containing MPn, a substrate-driven microbial succession occurred. Initially, the addition of glucose and nitrate resulted in a bloom of Vibrionales and a transcriptional profile dominated by glucose-specific PTS transport and polyhydroxyalkanoate biosynthesis. Transcripts associated with phosphorus (P) acquisition were also overrepresented and suggested that the addition of glucose and nitrate had driven the community to $\mathrm{P}$ depletion. At this point, a second community shift occurred characterized by the increase in C-P lyase containing microbes of the Vibrionales and Rhodobacterales orders. Transcripts associated with C-P lyase components were among the most highly expressed at the community level, and only C-P lyase clusters were recovered in a functional screen for MPn utilization, consistent with this pathway being responsible for the majority, if not all, of the methane accumulation we observed. Our results identify specific bacterioplankton taxa that can utilize MPn aerobically under conditions of $\mathrm{P}$ limitation using the C-P lyase pathway, and thereby elicit a significant increase in the dissolved methane concentration.

Keywords: methylphosphonate, phosphonates, genomics, transcriptomics, functional screens

\section{INTRODUCTION}

Methane $\left(\mathrm{CH}_{4}\right)$ is an important component of the global carbon cycle and a potent greenhouse gas (Reeburgh, 2007). Despite the fact that the world's oceans are a significant source of $\mathrm{CH}_{4}$ contributing $1-4 \%$ of the annual global emissions (Karl et al., 2008), the origin of oceanic $\mathrm{CH}_{4}$ is poorly understood. While most of the water column is undersaturated for $\mathrm{CH}_{4}$, the surface concentration is supersaturated relative to atmospheric levels in much of the world's oceans, suggesting that a net source of $\mathrm{CH}_{4}$ exists there (Lamontagne et al., 1973; Rudd and Taylor, 1980; Tilbrook and Karl, 1995). Since the ocean surface is welloxygenated and known methanogenenic pathways are inhibited by free oxygen (Rudd and Taylor, 1980), one prevalent hypothesis to explain $\mathrm{CH}_{4}$ supersaturation is the existence of methanogenesis within microanoxic aggregates. The ephemeral nature of anoxia in marine aggregates, however, might be predicted to limit the proliferation of slow-growing methanogens (Ploug et al., 1997). Recently it was hypothesized that microbial utilization of methylphosphonate (MPn) in P-limited surface waters might be a key source of aerobic $\mathrm{CH}_{4}$ production in the sea (Karl et al., 2008). MPn is the simplest of the phosphonate family of reduced $\mathrm{P}$ compounds which are characterized by the presence of a direct C-P bond instead of the more common C-O-P phosphate ester (Kittredge and Roberts, 1969). Nuclear magnetic resonance studies of high molecular weight DOP have shown that across oceans and throughout the water column, total phosphonates represent approximately one third of the dissolved organic $\mathrm{P}$, and that phosphonate content decreases with depth in high molecular weight dissolved organic material (DOM) relative to $\mathrm{C}$, indicating that phosphonates as a class of organic compounds are utilized by marine microorganisms (Clark et al., 1999; Kolowith et al., 2001). However, the chemical identity of marine phosphonates is only poorly understood. While compounds such as 2-aminoethylphosphonate (2-AEPn) (ciliatine) and 2-amino-phosphonopropionate (phosphonoalanine) had been found in many marine invertebrates (Horiguchi, 1984; Ternan et al., 1998), evidence of the occurrence of MPn had remained elusive. Recently, however, Metcalf et al. (2012) have shown that the abundant marine archaeon Nitrosopumilus maritimus encodes a novel pathway of MPn biosynthesis and produces an exopolysaccharide containing MPn esters (Metcalf et al., 2012). In addition, genes similar to those encoding MPn 
biosynthesis in $N$. maritimus were found to be relatively abundant in the planktonic marine microbial gene pool and were found in several scaffolds of the Global Ocean Survey database. Homologs of the MPn biosynthetic genes were also found in the abundant marine clade SAR11, suggesting that the concentration of MPn in seawater could be significant (Metcalf et al., 2012).

Microbial utilization of MPn is mediated by the C-P lyase pathway that hydrolyzes the C-P bond in a variety of aryland alkylphosphonates releasing the corresponding hydrocarbon (reviewed in Ternan et al., 1998; Quinn et al., 2007; White and Metcalf, 2007). In the case of MPn, C-P lyase activity yields $\mathrm{CH}_{4}$ that is released into the growth medium (Daughton et al., 1979). In Escherichia coli, where it is best characterized, the C-P lyase pathway is encoded in a 14 gene operon (phnCDEFGHIJKLMNOP) under the control of the $\mathrm{P}$ starvation Pho regulon (Metcalf and Wanner, 1991, 1993b; Wanner and Metcalf, 1992). Based on sequence and genetic analyses it was proposed that phnCDE encode a Pn-specific ABC transporter, phnG through phnM encode the minimal catalytic unit for C-P bond cleavage, and $p h n F, p h n N, p h n O$, and $p h n P$ encode regulatory or accessory proteins. The biochemical steps involved and the identity of the oxidized $\mathrm{P}$ product remained uncharacterized until a recent series of papers that culminated with the C-P lyase activity finally being reproduced in vitro with MPn as the substrate (Hove-Jensen et al., 2003, 2010, 2011; Kamat et al., 2011, 2013). According to the current model (Figure 1), PhnI (in the presence of PhnG, H, and L) and PhnM catalyze the conversion of MPn to 5-phospho- $\alpha$-D-ribosyl 1-alkylphosphonate (PRPn) which is the substrate of the C-P bond cleavage reaction catalyzed by
PhnJ. C-P bond cleavage releases $\mathrm{CH}_{4}$ and 5-phospho- $\alpha$-ribosyl1,2 -cyclic phosphate $(\mathrm{PRcP})$. In the next two steps catalyzed by $\mathrm{PhnP}$ and PhnN, PRcP is converted to 5-phospho- $\alpha$-D-ribosyl 1diphosphate (PRPP) which is funneled into primary metabolism. While there appears to be considerable variability in the composition of the C-P lyase gene cluster among bacteria, all clusters include the $p h n G-M$ genes that are essential for C-P bond cleavage (Huang et al., 2005).

Since the presence of the C-P lyase genes in the marine cyanobacterium Trichodesmium erythraeum ISM101 was reported by Dyhrman et al. (2006), several marine bacterial strains containing C-P lyase clusters have been shown to grow in culture using MPn as the sole P source. These include T. erythraeum ISM101, Ruegeria pomeyori DSS-3, Photobacterium angustum S14, and Planctomyces maris DSM8797 (Martinez et al., 2010; White et al., 2010). Moreover, C-P lyase clusters are abundant in the genomes of sequenced marine strains and metagenomic libraries of surface waters of the Sargasso Sea (present in $\sim 20 \%$ of bacteria) but less so at Station ALOHA in the North Pacific Subtropical Gyre ( $<1 \%$ of bacteria) (Martinez et al., 2010). Because one of the most prominent differences between the two ecosystems is that the surface dissolved inorganic phosphorus (DIP) concentrations are about an order of magnitude lower at the Sargasso Sea during the stratified summer months (CavenderBares et al., 2001), when the above samples were collected for sequencing, these results suggest that the ability to use $\mathrm{Pn}$ as a $\mathrm{P}$ source provides a competitive advantage in P-depleted waters (Coleman and Chisholm, 2010; Martinez et al., 2010). The high abundance of C-P lyase containing microbes in P-depleted waters

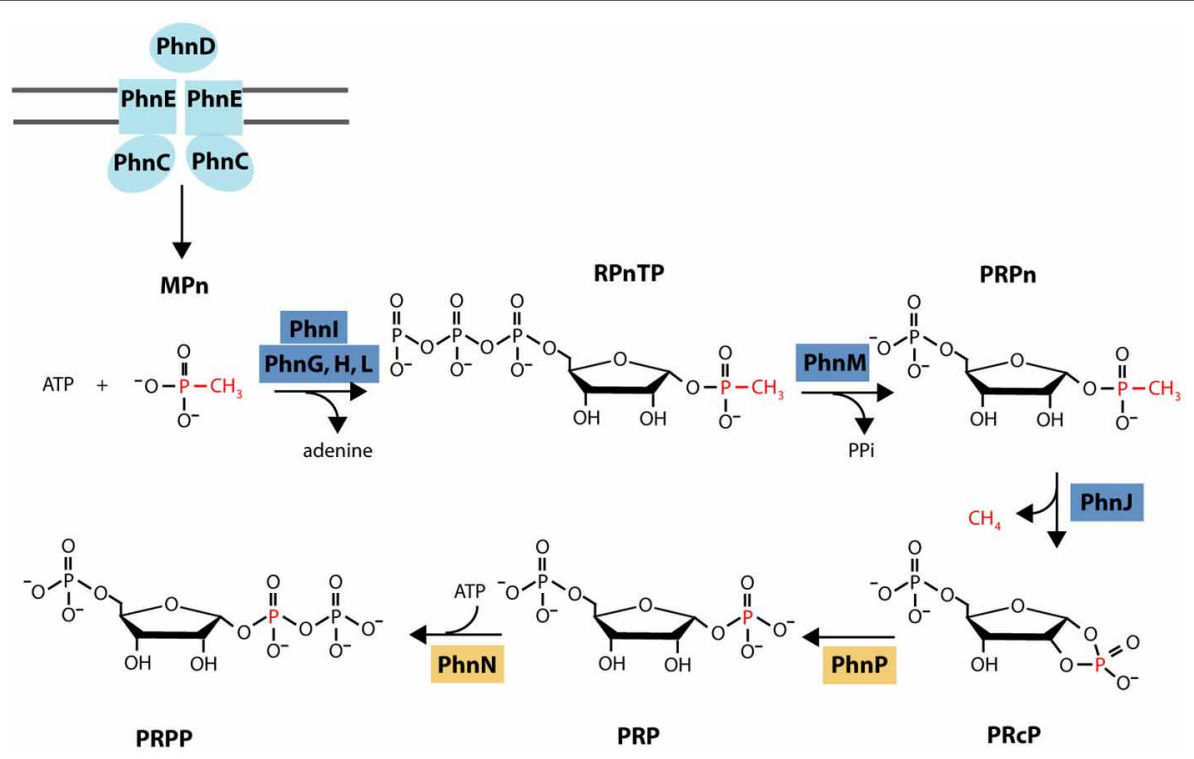

FIGURE 1 | Current biochemical model for MPn degradation. MPn is transported into the cytoplasm by the Pn-specific ABC transporter system integrated by $\mathrm{PhnC}, \mathrm{PhnD}$, and $\mathrm{PhnE}$. In the cytoplasm, Phnl catalyzes the conversion of MPn and ATP to $\alpha$-D-ribose-1methylphosphonate-5-triphosphate (RPnTP) and adenine in the presence of PhnG, H, and L. PhnM is a phosphatase that hydrolyzes RPnTP to form 5-phospho-a-D-ribosyl 1-alkylphosphonate (PRPn) which is the substrate of the C-P bond cleavage reaction catalyzed by PhnJ. C-P bond cleavage releases $\mathrm{CH} 4$ and 5-phospho-a-ribosyl-1,2-cyclic phosphate (PRcP). In the next two steps catalyzed by $\mathrm{PhnP}$ and $\mathrm{PhnN}, \mathrm{PRcP}$ is converted to 5-phosphoa-D-ribosyl 1-diphosphate PRPP which is funneled into primary metabolism. Protein color coding as in gene cluster diagram (Figure 8). Diagram modified from (Zhang and Van Der Donk, 2012). 
could potentially result in significant MPn-driven $\mathrm{CH}_{4}$ production in these waters (Karl et al., 2008). Remarkably, the experiments by Karl et al. (2008) showed that even at Station ALOHA, incubation of seawater samples with MPn under amendment conditions leading to $\mathrm{P}$-stress resulted in $\mathrm{CH}_{4}$ production indicating that despite the low abundance of C-P lyase clusters, the potential exists for MPn-driven $\mathrm{CH}_{4}$ production. To better characterize the microbes, biochemical and regulatory processes underlying this important process, we analyzed the changes in bacterioplankton community structure, gene content and gene expression that occurred after MPn amendment. Our results revealed a temporal succession of microbial taxa and metabolic process leading to the proliferation of initially low-abundance C$\mathrm{P}$ lyase-containing microbes, and identified metabolic pathways and regulatory elements mediating the community response to nutrient addition.

\section{RESULTS}

\section{EXPERIMENTAL DESIGN, METHANE PRODUCTION, AND CELL COUNTS}

Previous experiments have shown that the natural surface microbial community at Station ALOHA in the North Pacific Subtropical Gyre rapidly consumed exogenous MPn and produced $\mathrm{CH}_{4}$ under aerobic conditions in $75 \mathrm{~m}$ water samples that had been amended with $100 \mu \mathrm{M}$ glucose, $16 \mu \mathrm{M}$ nitrate, and $1 \mu \mathrm{M}$ MPn (referred to hereon as Glc+N+MPn) (Karl et al., 2008). In order to identify the microbes and gene functions mediating this process, we performed parallel metagenomic and metatranscriptomic analyses under similar enrichment conditions. Although additions of Glc $+\mathrm{N}$ were artificially high, we chose these conditions because they could promote the growth of indigenous MPn-utilizing microbes and thus facilitate the detection of MPn degradation genes normally found in low frequency in this environment (Karl et al., 2008; Martinez et al., 2010). Seawater was collected from 75-m depth below the mixed layer and above the deep chlorophyll maximum (Figure S1) and used immediately to set up 3 microcosm perturbation experiments as follows (Figure S2): B1, no amendment control; B2, Glc $+\mathrm{N}$ amendment with no added P source; and B3, Glc $+\mathrm{N}+\mathrm{MPn}$ amendment. DNA samples were taken at the beginning and at the end of the experiment for genomic analyses. In addition, subsamples were taken at $12 \mathrm{~h}$ intervals for community RNA extraction and dissolved $\mathrm{CH}_{4}$ measurements. The concentration of $\mathrm{P}$ in the unamended water was $51 \mathrm{nmol} \mathrm{l}^{-1}$, within the typical range for the upper water column of the North Pacific Subtropical Gyre (Karl et al., 2008).

The initial observed dissolved $\mathrm{CH}_{4}$ concentration in all three microcosms (2.6-3.2 nM) is typical of the upper water column in the North Pacific Subtropical Gyre (Karl et al., 2008). As was the case in the previous experiments, a significant increase in dissolved $\mathrm{CH}_{4}$ was observed only after $\mathrm{Glc}+\mathrm{N}+\mathrm{MPn}$ addition (B3) indicating that exogenous MPn was being converted to $\mathrm{CH}_{4}$ (Figure 2A). Elevated dissolved $\mathrm{CH}_{4}$ concentration compared to controls was first observed in $\mathrm{B} 3$ after $12 \mathrm{~h}$ of incubation and its concentration increased during the course of the experiment. A maximum $\mathrm{CH}_{4}$ concentration of $16.3 \mathrm{nM}$ was achieved after $48 \mathrm{~h}$ of incubation representing an almost 6-fold increase over the initial concentration. These results are similar to those of previous experiments (Karl et al., 2008) although the observed $\mathrm{CH}_{4}$ concentrations were lower, likely because we did not use gas-tight vessels for the large volume microcosms.

While the cell numbers in the control microcosm increased only slightly during the course of the experiment, the number of cells increased significantly in both treatments starting $24 \mathrm{~h}$ after nutrient addition (Figure 2B). Flow cytometry analyses revealed that the increase was due to the appearance of specific populations of larger, high DNA-content cells which represented $30 \%$ of total cells with an approximate concentration of $2.6 \times 10^{5}$ cells/ml (Figure 2C). Cell numbers and population distributions were identical in both amendments at the 24 and $36 \mathrm{~h}$ samples, suggesting that the observed changes were due to the Glc+N addition, while a distinct population unique to the Glc $+\mathrm{N}+\mathrm{MPn}$ treatment appeared in the $48 \mathrm{~h}$ sample $\left(\sim 4 \times 10^{5}\right.$ cells $/ \mathrm{ml}$, or $29 \%$ of total cells). At the final $48 \mathrm{~h}$ time point, the cell counts are 155 and $210 \%$ higher than the control for the Glc+N and Glc $+\mathrm{N}+\mathrm{MPn}$ treatments, respectively.

\section{THE ABUNDANCE OF C-P LYASE GENES SIGNIFICANTLY INCREASES AFTER MPn AMENDMENT}

The increase in $\mathrm{CH}_{4}$ concentration suggested the involvement of the C-P lyase pathway in MPn utilization. We analyzed the frequency of 6 genes encoding catalytic functions in this pathway ( $p h n G, p h n H$, phnI, $p h n J$, $p h n M$, and $p h n N$ ) in community genomic DNA (gDNA) samples collected at the beginning and the end of the experiment $(48 \mathrm{~h})$. In addition to the C-P lyase genes, we included in the analyses other phosphonate-utilization genes previously identified in marine environments: $p h n A$, encoding phosphonoacetate hydrolase, and phnW, phnX, phnY, and phnZ involved in 2-AEPn utilization (Quinn et al., 2007; Gilbert et al., 2009; Martinez et al., 2010). The recA gene was used as a reference single copy gene to normalize the abundance of the MPn degrading pathway genes. For each analyzed gene, abundance is expressed as the percentage of all bacteria containing the gene in question, based on the assumption that recA is present as a single copy gene in every genome. As it has been previously shown for surface waters in this region (Karl et al., 2008; Martinez et al., 2010), the frequency of phn genes was extremely low at the beginning of the experiment and after $48 \mathrm{~h}$ in the unamended microcosm (Table 1). Of the non C-P lyase phn genes analyzed, only the phnW and $p h n X$ encoding enzymes of the phosphonatase pathway for 2-AEPn utilization increased significantly in the Glc $+\mathrm{N}$-amended microcosm (in $~ 28 \%$ of bacteria after $48 \mathrm{~h}$ ). Phosphonatase gene abundance also increased but to a lesser extent in the Glc+N+MPn microcosm. Thus, the observed increased abundance of $p h n W$ and $p h n X$ does not appear to be MPn-driven, consistent with the fact that MPn is not a substrate for this pathway (Quinn et al., 2007). In contrast, the frequency of C-P lyase genes increased significantly only after Glc $+\mathrm{N}+\mathrm{MPn}$ amendment. If we average abundance across all six analyzed C$\mathrm{P}$ lyase genes, $40 \%$ of all bacteria are estimated to contain C-P lyase clusters after $48 \mathrm{~h}$, compared to less than $1 \%$ at the beginning of the experiment. The vast majority of these hits are most similar to those of sequenced genomes of Rhodobacterales and Vibrionales (52\% and $46 \%$ of all C-P lyase hits, respectively) 


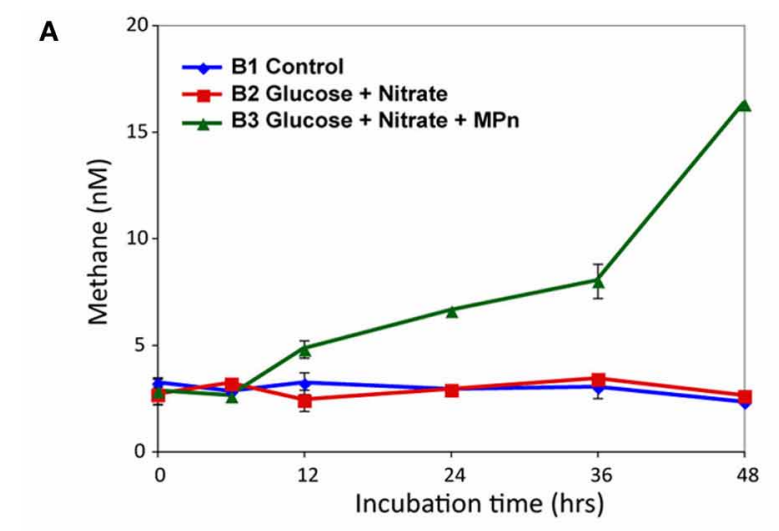

C
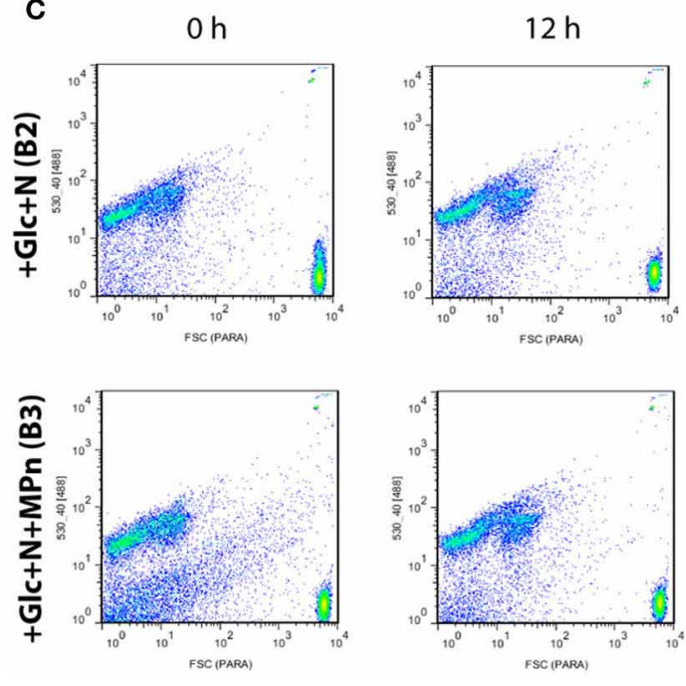
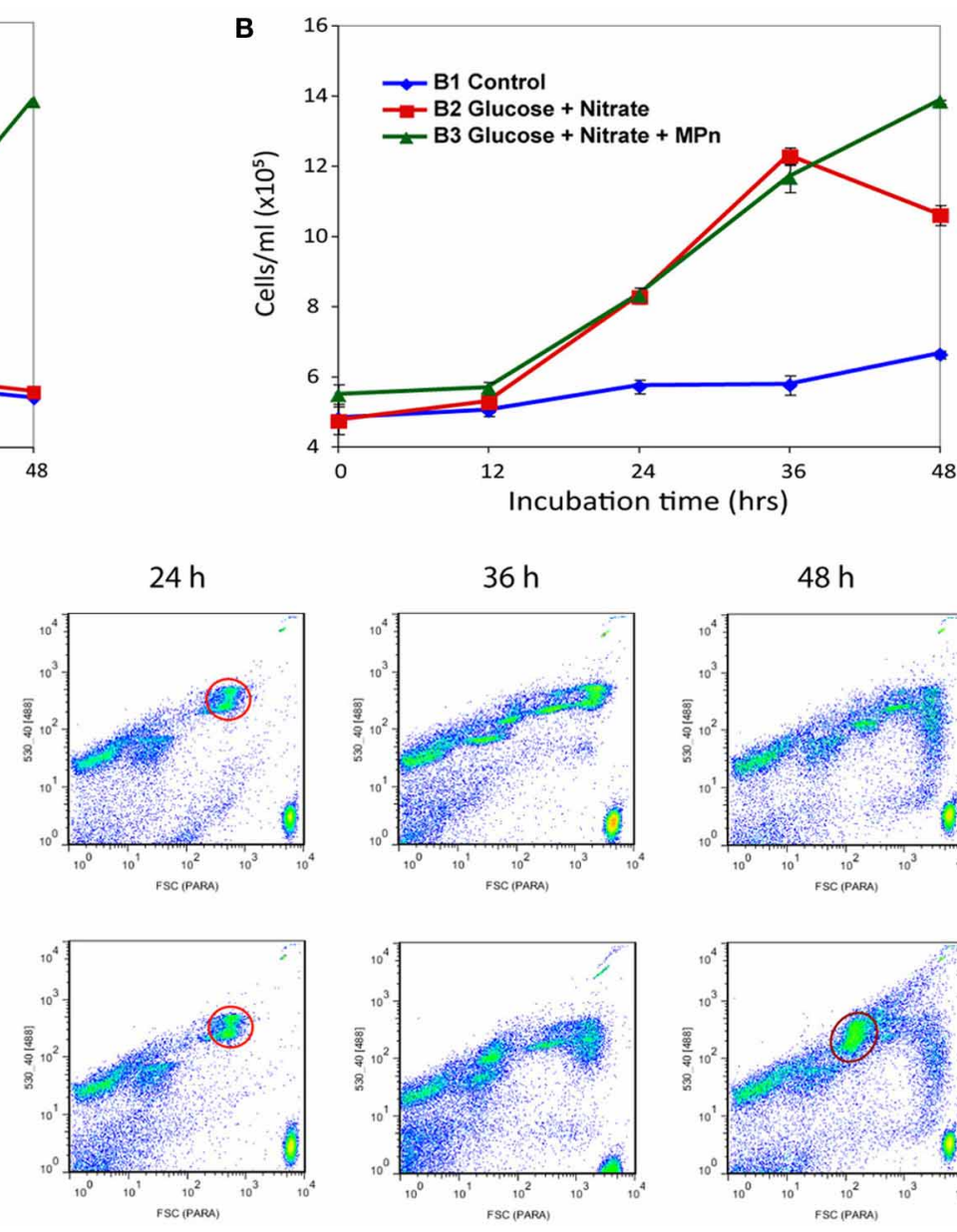

$24 \mathrm{~h}$
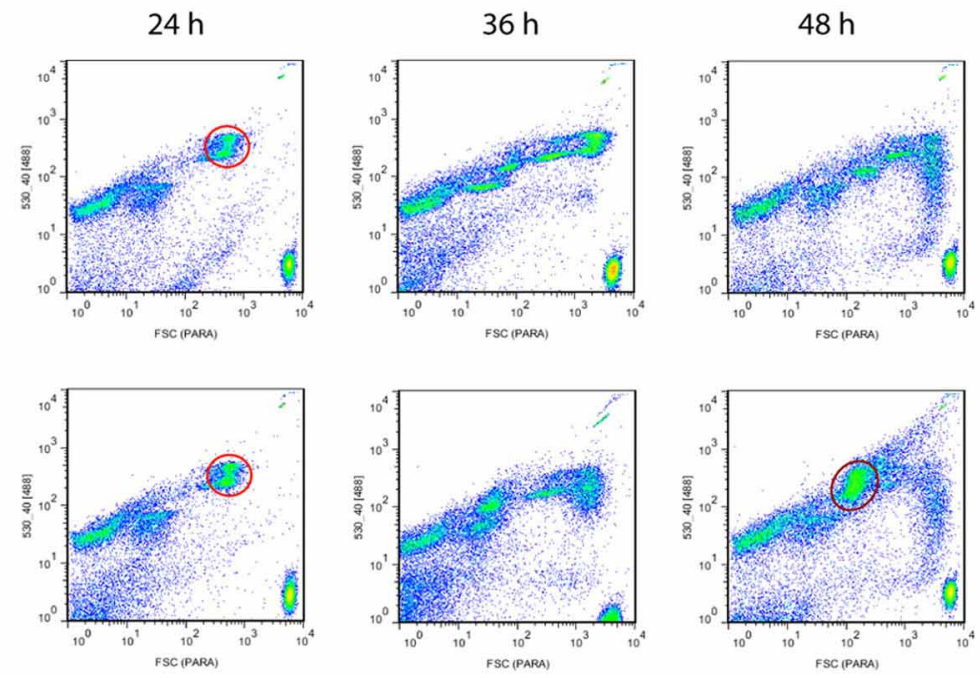

FIGURE 2 | $\mathrm{CH}_{\mathbf{4}}$ accumulation and cell number dynamics during $\mathbf{4 8} \mathrm{h}$ microcosm incubations. Three microcosms containing $20 \mathrm{~L}$ of sea water were amended as follows: B1: no amendment control; B2: amended with $100 \mu \mathrm{M}$ glucose and $16 \mu \mathrm{M}$ nitrate; B3: amended with $100 \mu \mathrm{M}$ glucose, $16 \mu \mathrm{M}$ nitrate, and $1 \mu \mathrm{M} \mathrm{MPn}$. Microcosms were incubated for $48 \mathrm{~h}$ and subsampled at $12 \mathrm{~h}$ intervals for $\mathrm{CH}_{4}$ measurements, flow cytometry, and community RNA. (A) $\mathrm{CH}_{4}$ accumulation in amended surface seawater samples. Dissolved methane concentration increases above background only in the Glc+N+MPn microcosm starting $12 \mathrm{~h}$ post amendment. (B) Flow cytometric counts of SYBR-stained microbial cells from the control and treatments. (C) Green fluorescence and forward scatter plots of treatment samples. The cell number increase is largely due to the appearance of distinct high DNA-content microbial populations. The first of such populations (highlighted in red) appeared in both treatments at $24 \mathrm{~h}$ and represented $\sim 30 \%$ of the cells $\left(2.6 \times 10^{5} \mathrm{cells} / \mathrm{ml}\right)$ at that time point. The pattern remains similar between treatments at later time points with the exception of a unique large population that appears in the Glc $+\mathrm{N}+\mathrm{MPn}$ microcosm $48 \mathrm{~h}$ after addition (circled in orange) that represents $\sim 29 \%$ of the total cell counts at that time $\left(\sim 4 \times 10^{5}\right.$ cells $\left./ \mathrm{ml}\right)$. Two micrometer fluorescent beads are at the bottom right of each panel.
(Table S1) suggesting that these two groups mediate the observed $\mathrm{CH}_{4}$ production. While the Rhodobacterales phn top hits were equally distributed across several species, 73 of the 74 identified Vibrionales sequences are most similar to those of a single sequenced strain, V. nigripulchritudo ATCC27043.

\section{MICROBIAL COMMUNITY STRUCTURE}

The changes in microbial community composition were assessed in more detail by taxonomic classification of protein-encoding metagenomic and metatranscriptomic reads. As expected, typically abundant planktonic bacterial taxa such as Prochlorales (Prochlorococcus) and Ricketsiales (Pelagibacter) were highly represented in the initial gDNA sample, and their abundance remained fairly constant over the course of the experiment in the unamended microcosm (Figure 3). In contrast, large shifts in community composition were observed in both the $\mathrm{Glc}+\mathrm{N}$ and Glc+N+MPn treatments. In the Glc+N microcosm, the decrease in the relative abundance of Prochlorales and Ricketsiales was accompanied by a large increase in the abundance of Gammaproteobacteria of the Vibrionales order (59\% of assigned reads, compared to less than $1 \%$ in the control). A dramatic increase in the abundance of Vibrionales (44\%) was also observed in the Glc+N+MPn-amended microcosm compared to the no amendment control, but is accompanied in this case by a large increase in the abundance of Alphaproteobacteria of the Rhodobacterales order (27\% of assigned reads vs. $4 \%$ in the controls), and to a much lesser extent, by an increase in Alteromonadales ( $4.6 \%$ vs. less than $2.2 \%$ in controls). Similar trends were observed for rRNA taxon abundance in metagenomic samples (Figure S3). 
Table 1 | Abundance of phn genes in genomic DNA pyrosequencing libraries.

\begin{tabular}{|c|c|c|c|c|c|}
\hline \multirow[t]{2}{*}{ Substrate } & \multirow[t]{2}{*}{ Gene } & \multirow{2}{*}{\begin{tabular}{l}
\multicolumn{1}{c}{ TO } \\
No \\
addition
\end{tabular}} & \multicolumn{3}{|c|}{$\operatorname{TF}(48 h)$} \\
\hline & & & $\begin{array}{l}\text { No } \\
\text { addition }\end{array}$ & $\mathbf{G l c}+\mathbf{N}$ & $\begin{array}{l}\text { Glc+N + } \\
\text { MPn }\end{array}$ \\
\hline \multirow{6}{*}{$\begin{array}{l}\text { Alkyl- } \\
\text { phosphonates }\end{array}$} & $p h n G$ & 0 & 0 & 0 & 47 \\
\hline & phnH & 0 & 0 & 0 & 15 \\
\hline & phnl & 0 & 0 & 4 & 38 \\
\hline & phnJ & 0 & 1 & 1 & 53 \\
\hline & phnM & 0 & 0 & 2 & 67 \\
\hline & $p h n N$ & 0 & 0 & 3 & 24 \\
\hline $\begin{array}{l}\text { Phos- } \\
\text { phonoacetate }\end{array}$ & phnA & 2 & 6 & 4 & 7 \\
\hline \multirow{2}{*}{$\begin{array}{l}\text { 2-Aminoethyl- } \\
\text { phosphonate }\end{array}$} & phnW & 6 & 5 & 25 & 5 \\
\hline & $p h n X$ & 0 & 0 & 31 & 5 \\
\hline \multirow{3}{*}{$\begin{array}{l}\text { 2-Aminoethyl- } \\
\text { phosphonate }\end{array}$} & phnY & 0 & 3 & 0 & 0 \\
\hline & $p h n Z$ & 0 & 0 & 4 & 9 \\
\hline & recA & 100 & 100 & 100 & 100 \\
\hline
\end{tabular}

Results expressed as \% of microorganisms estimated to contain gene of interest, assuming recA is present in single copy in every bacterium (Martinez et al., 2010). Significance cut-off bit $>50$.

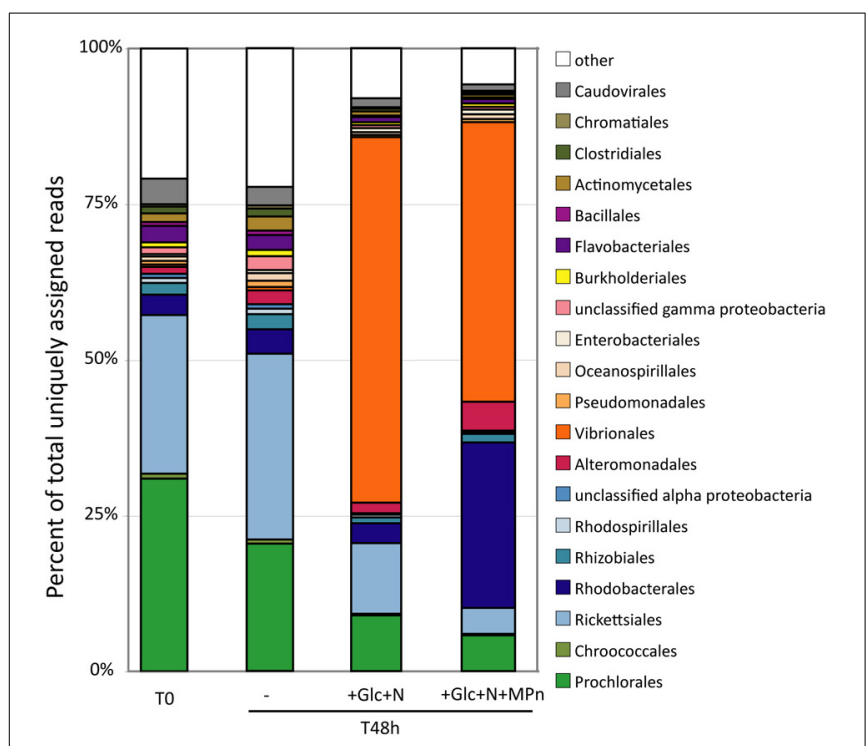

FIGURE 3 | Microbial population composition assessed by taxonomic classification of protein-coding metagenomic reads at the order level. Only taxonomic groups that represent $>1 \%$ of total assigned reads in at least one dataset have been included with all other groups binned together with unassigned reads. Abundance expressed as the percentage of reads assigned to each taxon divided by the total number of assigned reads in each database.

The taxonomic analysis of the intermediate metatranscriptomic samples revealed that up to the $36 \mathrm{~h}$ time point, both amended microcosms appeared to undergo parallel shifts in community composition with the large Vibrionales bloom taking place between 12 and $24 \mathrm{~h}$, and continuing at the $36 \mathrm{~h}$ time point (Figure 4). This signal was due in the most part to one taxon, V. splendidus ATCC27043 (97\% average id), for both amendments (Figures 4, S4). The fact that both microbial communities underwent this change suggests that the $V$. splendidus bloom was driven by the addition of Glc+N. While V. splendidus ATCC27043 remained the most abundant taxon in the $48 \mathrm{~h}$ cDNA and gDNA samples of the Glc $+\mathrm{N}$-amended microcosm, the low levels of C-P lyase genes in the $48 \mathrm{~h}$ metagenomic samples (Table 1) indicate that this population does not have the capacity to utilize MPn.

The community composition profiles of the amended microcosms diverged only at the $48 \mathrm{~h}$ final time point when the large relative increase of Rhodobacterales was observed only in the $\mathrm{Glc}+\mathrm{N}+\mathrm{MPn}$ microcosm (Figure 4). At the taxon id level, these reads were equally distributed across many species with relatively low average similarity (78-82\% amino acid identity) suggesting that the blooming Rhodobacterales have no close sequenced relatives (Figure S4). The relative abundance of Bacillales also increased in the $48 \mathrm{~h}$ transcriptome although to a lesser extent and many of those reads corresponded to hypothetical bacteriophage sequences which could compromise their taxonomic assignment. Finally, the relative abundance of Vibrionales decreased in the $48 \mathrm{~h}$ Glc $+\mathrm{N}+\mathrm{MPn}$ transcriptome but more importantly, the abundance of $V$. splendidus sequences decreased significantly and a distinct V. nigripulchritudo ATCC 27043-like population (89\% average id) became the most abundant taxon id at $48 \mathrm{~h}$ representing 15 and $32 \%$ of all assigned reads in the cDNA and gDNA samples, respectively (Figures 4, S4). Not only were V. nigripuchritudo and Rhodobacterales the same groups identified above in the taxonomic analysis of C-P lyase genes (Table S1), but combined they represented $45 \%$ of the assigned protein-coding reads at the metagenomic level, consistent with the estimated $\sim 40 \%$ abundance of C-P lyase-containing microbes by the $\mathrm{rec} A$ normalization method. Taken together, these results indicate that the $\mathrm{Glc}+\mathrm{N}+\mathrm{MPn}$ amendment led to a succession in the bacterioplankton population comprising an initial Glc+N-driven bloom of $V$. splendidus which was replaced by a MPn-driven increase in Rhodobacterales and V. nigripulchritudo populations. The apparent delay between the observed increase in dissolved $\mathrm{CH}_{4}$ concentration which started $12 \mathrm{~h}$ post- amendment (Figure 2 ), and the detection of MPn-driven population shift at $48 \mathrm{~h}$ could be the result of the limited sequencing depth and the lower abundance of these groups in the initial starting community.

It should also be noted that despite the increase in dissolved $\mathrm{CH}_{4}$ concentration observed in the Glc+N+MPn amended microcosm, we could not detect a significant increase in the relative proportion of reads assigned to any known aerobic $\mathrm{CH}_{4}$-oxidizing marine bacterial groups: (Methylococcales, Methylocystaceae, Verrucomicrobia, and Methylophaga spp.) (Hanson and Hanson, 1996; Dunfield et al., 2007; Neufeld et al., 2007).

\section{FUNCTIONAL GENE EXPRESSION TRENDS IN METATRANSCRIPTOMIC SAMPLES}

In order to examine the functional processes underlying the community shifts observed in the amendments, bulk community 


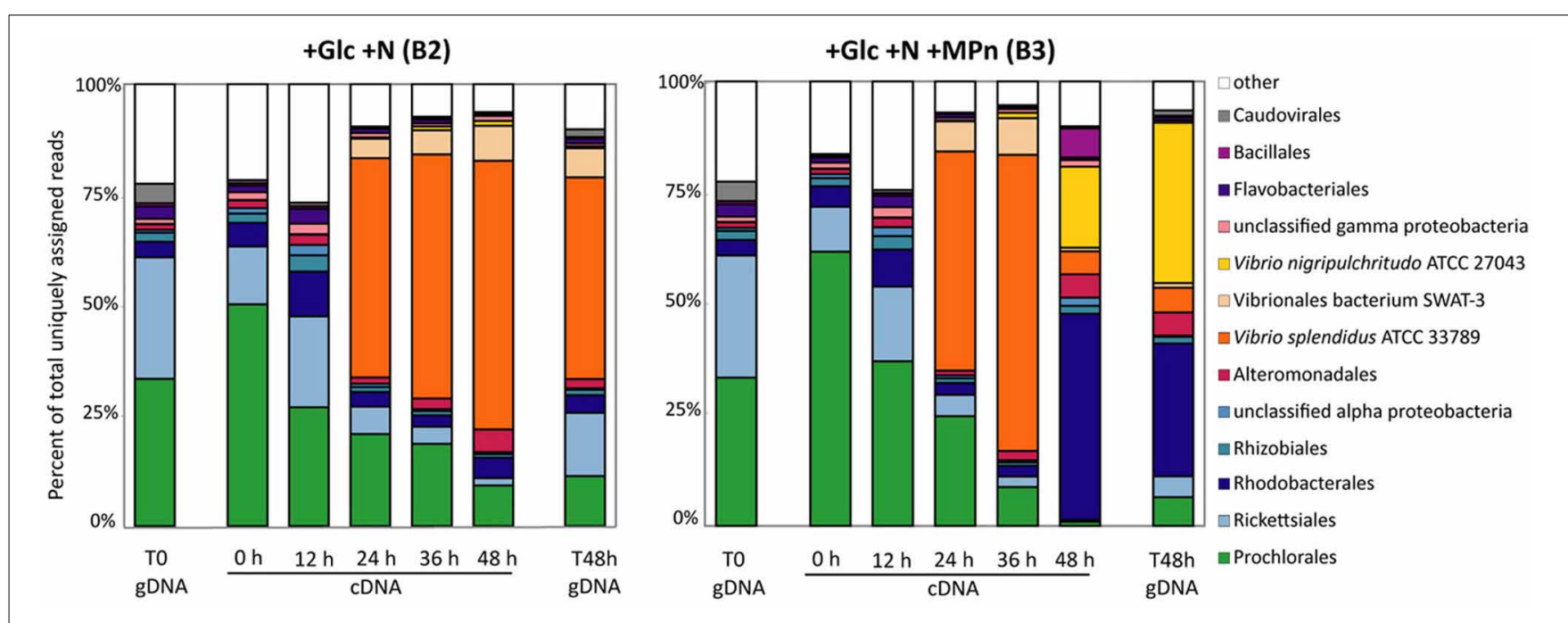

FIGURE 4 | Microbial population composition of amended microcosms assessed by taxonomic classification of protein-coding

metatranscriptomic reads. Abundance expressed as the percentage of reads assigned to each taxon divided by the total number of non-rRNA, non-sRNA assigned reads in each database. Taxonomic classification is shown at the order level except for the Vibrionales where read numbers for the thee main taxon id are shown. Only taxonomic groups that represent $>3 \%$ of total assigned reads in at least one dataset have been included.
cDNA reads were assigned to Kyoto Encyclopedia of Genes and Genomes (KEGG) functional categories and their relative abundance was compared across metatranscriptomes. For an initial assessment of the magnitude of functional gene expression changes, we calculated the fraction of KEGG orthologs whose abundance was significantly different (FDR-corrected $P$-value $<$ 0.05) in the treatments compared to the unamended control at each time point. While this number was less than $5 \%$ in the 0 and $12 \mathrm{~h}$ cDNA samples, the percentage of functional KEGG orthologs with significant abundance changes relative to the unamended control increased significantly for both treatments in the $24 \mathrm{~h}$ sample $(17 \%)$ and remained high throughout the treatment (Table S2). Not only were lower percentages of significant changes observed when the two amendments were compared directly against each other specially at the $24 \mathrm{~h}$ sample, but both amendments caused similar changes in the most abundant transcripts (Table S3) indicating that the shifts in functional gene expression were caused in part by the addition of Glc $+\mathrm{N}$, in good agreement with the changes observed in taxonomic composition.

Clustering of the metatranscriptomes according to their KEGG pathway profiles results in two clearly distinct sample groups (Figure 5). The first group includes all the unamended control samples as well as the amended transcriptomes for the 0 and $12 \mathrm{~h}$ time points. Within this group, clustering appears largely due to the influence of the diel cycle, with high day time expression of photosynthetic and carbon fixation pathways and night time increase in oxidative phosphorylation and TCA cycle. This pattern is consistent with previously reported diel expression patterns in the surface waters (Zinser et al., 2009; Shi et al., 2010, 2011; Ottesen et al., 2011). In contrast, the metatranscriptomes of both amendments diverge from the control starting with the $24 \mathrm{~h}$ sample and form a separate amendment-driven cluster. Within this group, metatranscriptomes cluster by collection time and not by the specific amendment suggesting that a significant portion of the functional profile changes are driven by the Glc $+\mathrm{N}$ addition. Overall, after the $24 \mathrm{~h}$ time point the amendment metatranscriptomes are characterized by a large increase in the abundance of transcripts associated with organic carbon uptake and utilization, phosphate metabolism, and two-component regulatory systems among other changes (Figure 6). High expression of the alkylphosphonate metabolism pathway, which consist of the genes encoding C-P lyase components, is the major difference between the Glc+N and Glc+N+MPn transcriptomes. The most significant trends in community expression changes are highlighted below.

\section{Phosphoenolpyruvate phosphotransferase system}

Transcripts encoding components of the phosphoenolpyruvate phosphotransferase system (PTS) for sugar assimilation were very highly enriched in both amended transcriptomes (Figure 6). Expression of the PTS pathway peaked $24 \mathrm{~h}$ post-amendment with over 50-fold increase in relative expression compared to the unamended control. At $24 \mathrm{~h}$, PTS transcripts constituted more than $3 \%$ of all assigned reads in both amendments compared to less than $0.1 \%$ in the B1 control (Table S5). Specifically, the most overrepresented transcripts included the glucose-specific components of the PTS (enzyme II subunits EIIA gluc and EIIB ${ }^{\text {gluc }}$ ) as well as components of the general phosphotransfer cascade enzyme I (EI) and histidine protein (HPr) (Table S6). Thus, all components required for the sequential transfer of the phosphate group from phosphoenolpyruvate to EI, to HPr, to EII ${ }^{\text {gluc }}$, and finally to glucose as it is translocated across the membrane (Cordaro, 1976), are highly induced upon amendment indicating a shift toward glucose utilization at the $24 \mathrm{~h}$ time point in both amended microcosms. Transcripts for the sucrose (scrA) and $\mathrm{N}$-acetylglucosamine-specific (nagE) EIIB components are also overrepresented in the amendment transcriptomes although to a lesser extent. 


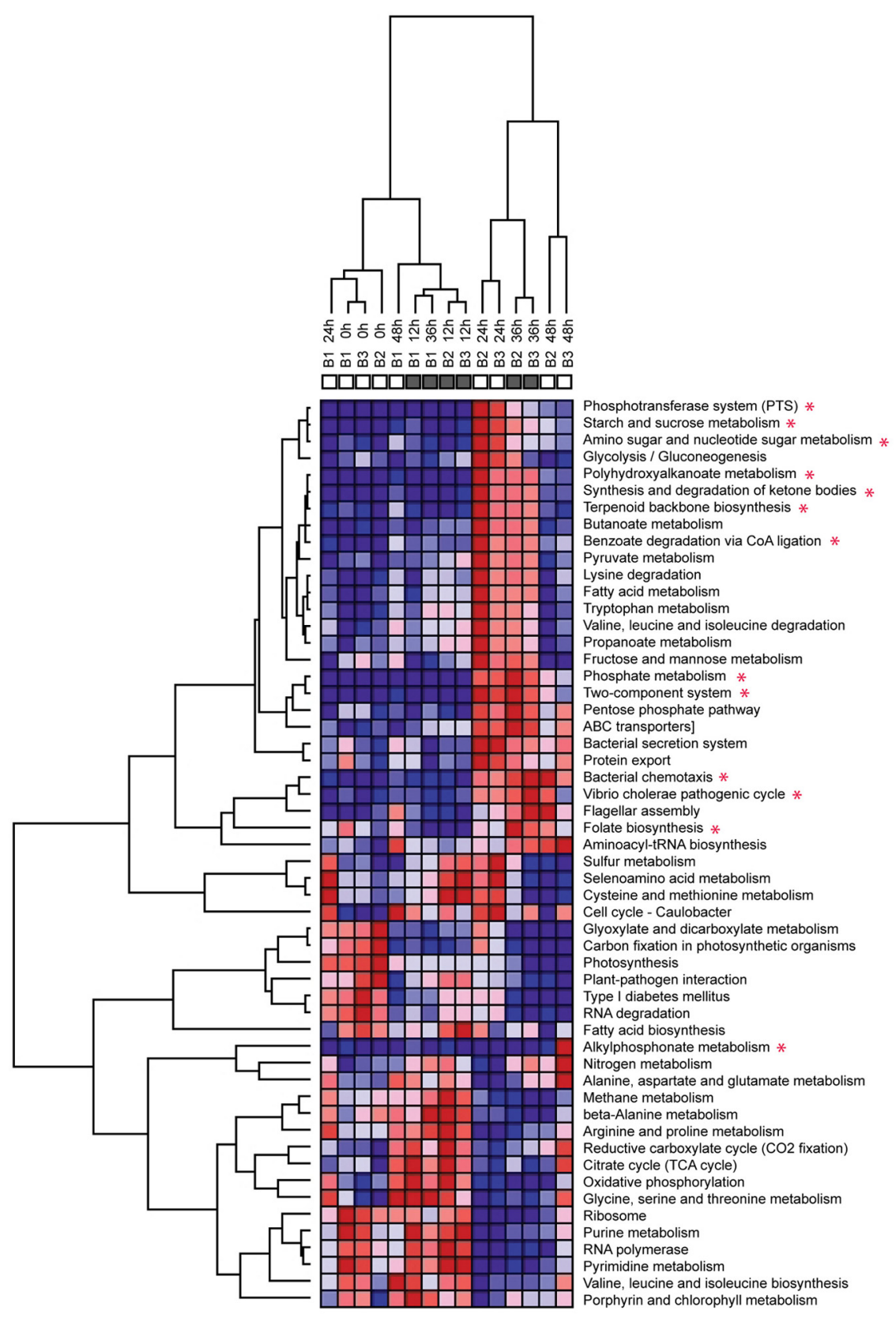

FIGURE 5 | Clustering of metatranscriptomics databases according to their KEGG pathway profiles. Heatmap shows relative distribution of protein-coding reads matching KEGG pathways. Red = high abundance, blue $=$ low abundance. Color scale is row (pathway) normalized. Only pathways representing more than $1 \%$ mapped reads in at least one dataset

\section{Polyhydroxyalkanoate biosynthesis}

Concomitant with the increased expression of the glucose PTS transport system, we observed an overrepresentation of transcripts associated with the synthesis of polyhydroxyalkanoate (PHA). PHAs are storage lipid compounds that accumulate when an essential nutrient becomes limiting under carbon excess conditions and serve as carbon and energy storage for maintenance of metabolism during starvation and growth resumption are included. Dendograms are based on hierarchical clustering of Pearson correlation coefficients for each pairwise comparison. KEGG pathways with at least 5 -fold overrepresentation compared to the no addition control in at least one time point are marked with an asterisk. Pathway abundance data from Table S5.

in many bacteria (Rehm and Steinbuchel, 1999; Waltermann and Steinbuchel, 2005). As was the case with PTS, expression of the PHA synthesis pathway peaked for both Glc+N and Glc $+\mathrm{N}+\mathrm{MPn}$ transcriptomes $24 \mathrm{~h}$ post-amendment ( 28 and 16-fold overrepresentation compared to control, respectively), and decreased gradually thereafter (Figure 6). Transcripts for all three enzymes required for PHA biosynthesis, acetyl-CoA acetyltransferase $(p h b A)$, acetoacetyl-CoA reductase $(p h b B)$, and 


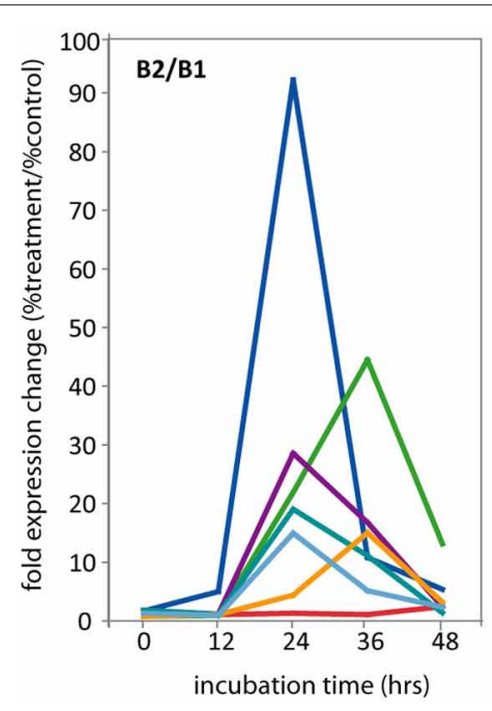

FIGURE 6 | Relative abundance of selected KEGG pathways in metatranscriptomic datasets. For each time point, abundance is expressed as fold expression change relative to the no amendment control ( $\%$ treatment/\%control). Left panel (B2/B1): Glc+N/no amendment control;
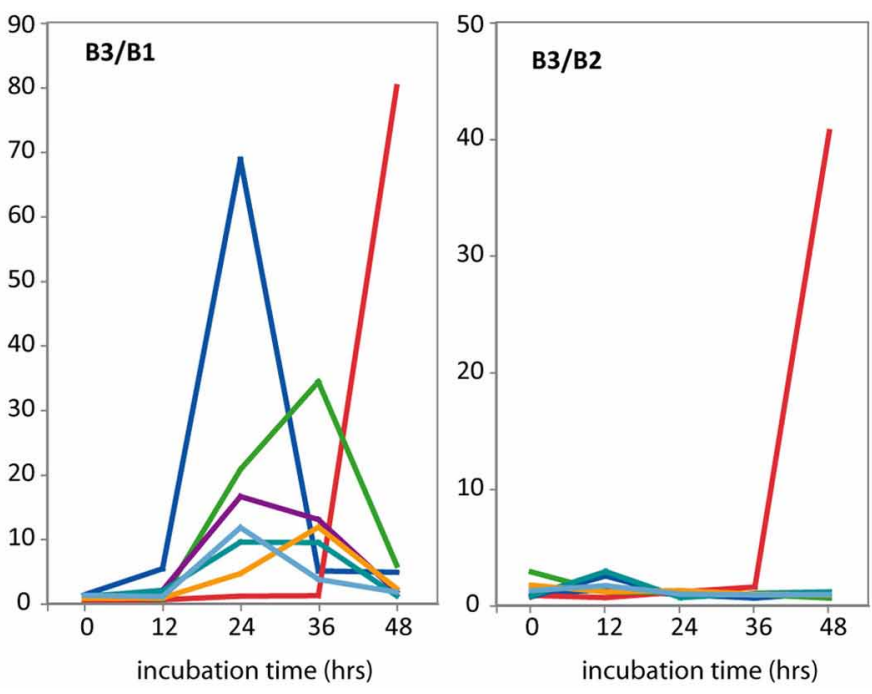

Middle panel (B3/B1): Glc+N+MPn/no amendment control; Right panel (B3/B2): $\mathrm{Gl}+\mathrm{N}+\mathrm{MPn} / \mathrm{Glc}+\mathrm{N}$. For simplicity, only KEGG pathways with 10-fold or more overrepresentation in at least one time point are included. Complete data found in Table S6. polyhydroxyalkanoate polymerase $(p h b C)$, were very significantly enriched, ranging from 10 - to more than 600-fold over control at $24 \mathrm{~h}$ (Table S6). The large number of transcripts for the acetoacetyl-CoA reductase observed at $24 \mathrm{~h}$ was enough to drive by itself an apparent increase of several other KEGG pathways including those for synthesis and degradation of ketone bodies, benzoate degradation, and terpenoid backbone biosynthesis. Because no other transcripts in those pathways showed similar increase in abundance, they will not be discussed further.

As observed for the PTS pathway, the majority of the transcripts associated with PHA biosynthesis are most similar to those of Vibrionales, in particular V. splendidus, which was the dominant taxon at this time. Accumulation of poly- $\beta$ hydroxybutyrate in vibrios has been previously observed in culture during the growth phase and when undergoing $\mathrm{P}$ starvation in the presence of excess glucose (Mårdén et al., 1985; Malmcrona-Friberg et al., 1986).

\section{Other carbohydrate utilization pathways}

Several additional KEGG pathways involved in carbohydrate metabolism are also overrepresented in the two amendments relative to control, most significantly the starch and sucrose metabolism and amino sugar and nucleotide sugar metabolism (Table S6). While at $24 \mathrm{~h}$ the transcripts for the glucose-specific components of the PTS described above dominate the signal in these pathways, transcripts associated with the utilization of chitin, starch and sucrose are overrepresented in the $48 \mathrm{~h}$ transcriptomes suggesting a shift toward more complex substrate utilization at the final time point for both amendments.

\section{Phosphate metabolism}

Transcripts associated with $\mathrm{P}$ acquisition systems were highly overrepresented in the transcriptomes of both amended microcosms indicating that the addition of Glc $+\mathrm{N}$ drove the microbial community into $\mathrm{P}$ starvation (Figure 6). The relative increase is observed starting at $24 \mathrm{~h}$ but it is at its maximum $48 \mathrm{~h}$ post-amendment ( 44 and 34 -fold increase after $\mathrm{Glc}+\mathrm{N}$ and Glc $+\mathrm{N}+\mathrm{MPn}$ addition, respectively). The most enriched transcripts include the phosphate-binding ( $p s t S$ ), permease $(p s t C)$, and ATP-binding ( $p s t B)$ components of the high affinity phosphate-specific ABC transporter (Table S6), which is known to be induced under $\mathrm{P}$ starvation in many organisms (Scanlan et al., 1993; Wanner, 1993; Dyhrman and Haley, 2006; Martiny et al., 2006; Dyhrman et al., 2007). The periplasmic phosphate-binding component pstS in particular is the most highly expressed KEGG ortholog in both amendments at 24 and $36 \mathrm{~h}$, and at $48 \mathrm{~h}$ in the Glc+N microcosm (Table S3). Also highly enriched were transcripts encoding alkaline phosphatases $p h o A$ and $p h o X$ which mediate utilization of dissolved organic $\mathrm{P}$ compounds under low phosphate conditions (Sebastian and Ammerman, 2009; Duhamel et al., 2010) again indicating a shift toward P-limitation after $\mathrm{Glc}+\mathrm{N}$ addition. Also enriched were the phosphate regulon two-component sensor ( $p h o R)$ and transcriptional regulator (phoB).

\section{Nitrogen metabolism}

Several transcripts associated with nitrogen metabolism were overrepresented in both amendments. In particular, the NADH-dependent catalytic subunit of the assimilatory nitrate reductase (nasA), and the large (nirB) and small (nirD) subunits of the $\mathrm{NAD}(\mathrm{P}) \mathrm{H}$-dependent nitrite reductase were significantly enriched $48 \mathrm{~h}$ post-amendment reflecting the assimilation of the allochthonous nitrate by sequential reduction to nitrite and ammonia (Moreno-Vivian et al., 1999). 


\section{Two-component systems, chemotaxis, and flagellar synthesis}

Another dramatic change in expression profile occurring in both amendment transcriptomes and thus, induced by the $\mathrm{Glc}+\mathrm{N}$ addition, is the overrepresentation of transcripts encoding two-component sensor systems starting $24 \mathrm{~h}$ post-amendment (Figure 6). Specifically, both components of the phosphatesensor system ( $p h o R / p h o B)$ were overrepresented, as well as those associated with carbon storage regulation ( $\operatorname{bar} A / u v r Y)$, autoin-

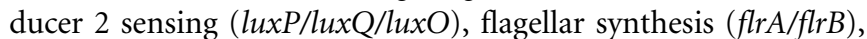
stress response $(r s t B / r s t A)$, redox state sensing $(\operatorname{arc} A)$, and $C 4$ dicarboxylate $(d c t B / d c t D)$ (Table S6). In addition, the chemotaxis sensor kinase (cheA) and response regulator components (cheV and cheY) were very significantly enriched (up to 35fold compared to control) as were the other components of the bacterial chemotaxis system controlling flagellar rotation ( $m c p$, cheR, cheB, and cheW). Also significant were the enrichment of the flagellar-specific sigma factor ( fliA) as well as many flagellar components and assembly proteins (Table S6). This pattern of two-component system transcript enrichment, similar to that observed after HMW DOM addition (McCarren et al., 2010), indicates a shift toward an "opportunistic" metabolic profile capable of sensing and reacting quickly to nutrient fluctuations (Polz et al., 2006; Lauro et al., 2009; Stocker, 2012).

\section{ABC transporters}

The amendments also resulted in an enrichment of transcripts associated with ABC transporters involved in ATP-driven nutrient uptake, but while some of those changes are common to both amendments, others are amendment specific. The main common $\mathrm{ABC}$ transporter increase was that of the phosphatespecific transporter discussed above ( $p s t S / p s t C / p s t A)$ but an enrichment of transcripts encoding components of the maltosespecific (malE/malF/malG) and glycerol-3-phosphate-specific transporters ( $u g p E / u g p A / u g p E$ ) are also observed (Table S6). The $\mathrm{Glc}+\mathrm{N}+\mathrm{MPn}$ transcriptome presented unique ABC transporter enrichments at the final $48 \mathrm{~h}$ time point for xylose $(x y l F / x y l H)$ and phosphonate transport ( $p h n D / p h n E / p h n C)$. These transcriptional changes are likely to be directly or indirectly MPn-driven. The phosphonate transporter expression changes are discussed in detail below.

\section{Other changes}

The lipoprotein NlpD exhibited one of the largest fold increases in both amendments starting at $24 \mathrm{~h}$ post addition (Table S6). $\mathrm{NlpD}$ is a component of the cell division machinery that regulates the activity of peptidoglycan-degrading amidases at the cytokinetic ring (Uehara et al., 2010) and thus its increase in expression is consistent with the observed bloom occurring in response to Glc $+\mathrm{N}$ addition at $24 \mathrm{~h}$ (Figure 2). A similar pattern was observed for $t a t B$ and $t a t A$ which encode components of the sec-independent twin-arginine translocation pathway (Lee et al., 2006). Interestingly secretion of the alkaline phosphatase PhoX, highly induced upon amendment, has been shown to take place by the TAT pathway (Monds et al., 2006).

\section{Small RNAs}

Since it is known that small regulatory RNAs (sRNAs) are abundant in marine microbial transcriptomic data (Shi et al., 2009) we examined the abundance of known sRNAs in our samples in an attempt to unveil possible sRNA-mediated regulatory mechanisms underlying the massive changes observed in the metabolic profile of the amended microcosms. Based on the Rfam 10.0 database (Gardner et al., 2009), we identified several sRNA families that were overrepresented after nutrient amendment (Table S7). The most significant change was the enrichment in sRNAs of the $c s r B / r s m B$ family which were barely detectable in the control transcriptome but increased significantly after $24 \mathrm{~h}$ and constituted more than $4 \%$ of the non rRNA reads at the $36 \mathrm{~h}$ time point for both amendments (Figure 7). Not surprisingly, the vast majority of the $c s r B$ reads were most similar to those of $V$. splendidus, the major taxon blooming $24 \mathrm{~h}$ after Glc $+\mathrm{N}$ addition. The CsrB (for carbon storage regulator) or RsmB (for repressor of stationary-phase metabolites) sRNAs use molecular mimicry to sequester multiple copies of the regulatory protein CsrA (or RsmA) away from their cognate mRNAs and thus alter their translation or turnover (reviewed in Romeo et al., 2013). Originally described in E. coli as a regulator of glycogen biosynthesis, CsrA is known to be a pleitropic regulator that, depending on the organism, controls central carbon flux, cell motility, biofilm formation, production of extracellular products, quorum sensing or pathogenesis (Babitzke and Romeo, 2007). Transcripts associated with several of these pathways were significantly enriched in the amended transcriptomes, as were the transcripts for the BarA/UvrY two-component system that regulates CsrB expression in response to unknown metabolic signals, suggesting that CsrB may play an important role in regulating gene expression in response to nutrient addition in our experiments. Other sRNAs whose abundance increases significantly in response to Glc+N addition include among others the glycine and lysine riboswitches (Table S7) again suggesting that sRNAs play a significant role in the response to environmental stimuli by bacterioplankton communities.

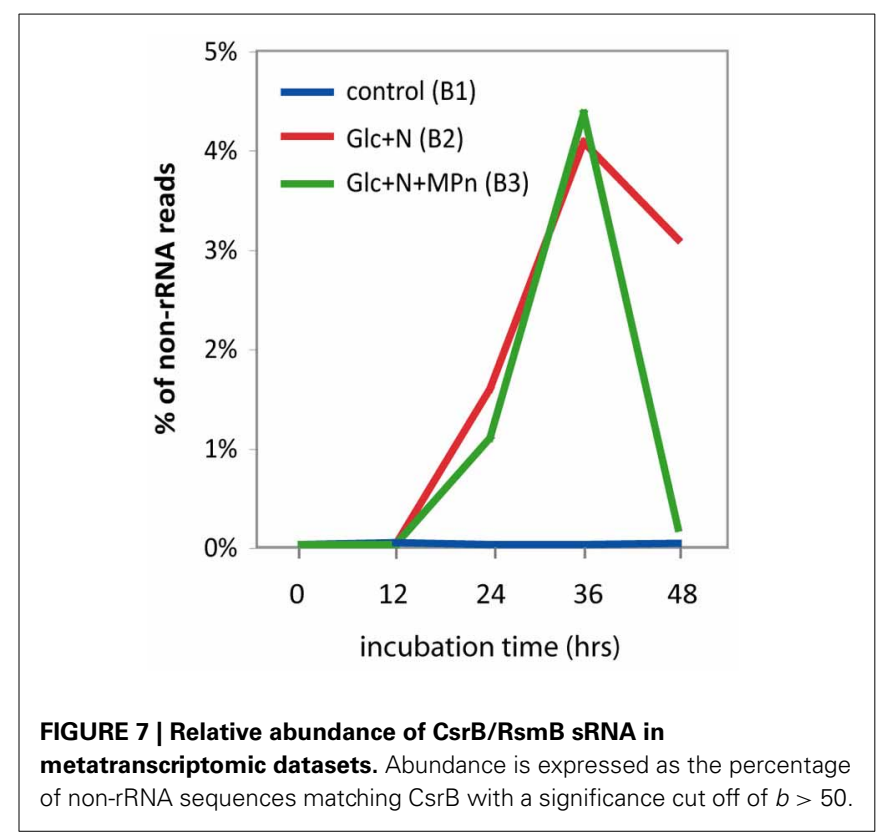




\section{Alkylphosphonate metabolism}

The major difference at the functional level between the two amendments is the overrepresentation of transcripts associated with the alkylphosphonate metabolism in the $48 \mathrm{~h}$ transcriptome of the Glc $+\mathrm{N}+\mathrm{MPn}$ microcosm (Figure 6). Specifically, alkylphosphonate metabolism expression was 80 -fold and 40-fold more abundant in this metatranscriptome than in the no amendment or Glc $+\mathrm{N}$ control, respectively. The enrichment is observed for all members of the C-P lyase pathway with the exception of phnO which was not detected in our sample (Table S6). PhnO is an alkylphosphonate $\mathrm{N}$-acetyltransferase recently implicated in utilization or detoxification of certain amino-phosphonates but in E. coli it is not required for MPn degradation in vivo or in vitro with purified enzymes (Errey and Blanchard, 2006; Hove-Jensen et al., 2012). Thus, all components known to be necessary for MPn utilization, including the phosphonate-specific $\mathrm{ABC}$ transporter $(p n h C D E)$, transcriptional regulator $(p h n F)$, as well as catalytic units (phnGHIJKLMNP) (Metcalf and Wanner, 1991, 1993a,b; Yakovleva et al., 1998), were highly enriched in the MPn $48 \mathrm{~h}$ transcriptome. The extent of the enrichment was high, 6- to 250-fold depending on the ortholog (Table S6). One of them, phnM, was among the top 10 most abundant orthologs in the $48 \mathrm{~h}$ MPn-containing sample $(0.5 \%$ of all reads mapped to KEGG but undetectable in the no-amendment control, Table S3).

The fact that no significant C-P lyase expression was detected at the earlier time points despite the fact that dissolved $\mathrm{CH}_{4}$ concentration was observed starting $12 \mathrm{~h}$ post-amendment is likely to be a combination of the low sequencing depth and the very low relative abundance of $\mathrm{C}$-P lyase-containing microbes in the original community (Table $\mathbf{1}$ ) which is in agreement with previous analyses in this environment (Karl et al., 2008; Martinez et al., 2010).

\section{$\mathrm{CH}_{4}$ utilization}

Given the significant increase in dissolved $\mathrm{CH}_{4}$ concentration observed in the Glc+N+MPn-amended microcosm, one might expect to see an increase in transcripts associated with $\mathrm{CH}_{4}$ utilization. Reads encoding the particulate ( $p m o A B C)$ or soluble ( $m m o B C D X Y Z$ ) methane monooxygenases catalyzing the first step in aerobic oxidation of $\mathrm{CH}_{4}$ (Hanson and Hanson, 1996) were not detected in either the metatranscriptome or metagenome. Similarly, there was no increase in the abundance of transcripts encoding the methyl-coenzyme $M$ reductase ( $m c r A B C D)$ or the sulfite reductase $(\operatorname{ds} A B)$ which have been used as markers for anaerobic methanotrophic archaea or their associated sulfate reducing bacteria, respectively (Havelsrud et al., 2011). These results, consistent with the absence of abundance shifts in known methanotrophic groups in the taxonomic profile, suggest that methanotrophy was not significantly induced under our experimental conditions and sequencing depth, most likely due to the short time course of the incubation, and competition for nutrients by other bacterial heterotrophs.

\section{FUNCTIONAL SCREENING FOR MPn UTILIZATION PATHWAYS}

We performed a functional screen for MPn degradation pathways in order to gain a better understanding of the phylogenetic origin and gene composition of the C-P lyase clusters identified through our metatranscriptomic analysis, and to identify any other existing MPn degradation pathways involving uncharacterized enzymes. This approach, which does not rely on any a priori sequence information has been successful in identifying novel Pn degradation pathways in a marine microbial metagenomic library (Martinez et al., 2010).

We prepared a fosmid library $(\sim 47,000$ clones with $40 \mathrm{~kb}$ average insert size for a total of $\sim 1.9 \mathrm{~Gb}$ content) using the $48 \mathrm{~h}$ metagenomic DNA from the Glc $+\mathrm{N}+\mathrm{MPn}$ microcosm and screened it for clones that could complement E. coli BW16787trfA (Martinez et al., 2010) for growth on MPn as the sole P source. This strain has a partial deletion in the phn operon $(\triangle p h n H I J K L M N O P)$ that renders it incapable of growing on $\mathrm{Pn}$, while still maintaining a functional Pn transporter encoded by phnCDE, the first three genes of the operon (Figure 8). After dereplication, we found that the 25 clones that allowed growth on MPn represented overlapping clones of 3 distinct fragments. A representative of each group was fully sequenced and all three were found to encode C-P lyase clusters (Table S8). Based on the phylogenetic affiliation of the best blast hits for each of the predicted encoded proteins, B3_TF_MPn_2 (19 clones) belongs to an Alphaproteobacterium of the Rhodobacteraceae family (66\% average protein identity across several Rhodobacteraceae genomes) while B3_TF_MPn_8 (4 clones) is highly similar to V. nigripulchritudo ATCC27043 (82\% average protein identity across the entire fosmid). Finally, the origin of the least abundant hit (B3_TF_MPn_1, 2 clones) is likely to be a Gammaproteobacterium of the Alteromonadales order, with the oligotrophic marine Gammaproteobacterium IMCC1989 (Jang et al., 2011) as the best hit for 12 of its 30 predicted proteins. The phylogenetic origin of the MPn screen hits and approximate relative abundance were consistent with the community changes observed in the final $48 \mathrm{~h}$ time point of the MPn amendment (see Figure 3). In addition, the vast majority $(80 \%)$ of the C-P lyase gDNA reads identified (Table 1) could be assigned to the C-P lyase clusters in B3_TF_MPn2 (Rhodobacterarales) and B3_TF_MPn_8 (V. nigripulchitudo) using a stringent 95\% nucleotide identity cutoff indicating that these two clusters represent the majority of the C-P lyase genes in our samples. Furthermore, the mean expression ratio (RNA/DNA) of the C$\mathrm{P}$ lyase cluster genes in the final $48 \mathrm{~h}$ sample is more than 10 times higher than that of non-C-P lyase genes in the same fosmids (Figure S5) underscoring the important role of the C-P lyase in MPn metabolism under our conditions.

All three marine C-P lyase clusters identified contained all the genes required for MPn cleavage in E. coli (Figure 1). They include those encoding the phosphonate-specific ABC transporter system $(p h n C, p h n D$, and $p h n E)$, the regulatory gene $p h n F$, and $p h n G$ through $p h n M$ which encode required catalytic functions to release $\mathrm{CH}_{4}$ from MPn (Metcalf and Wanner, 1991, 1993a,b; Yakovleva et al., 1998). A few significant differences with the E. coli phn cluster were observed. For example, phnP which encodes a phosphoribosyl cyclic diesterase that cleaves the product of the C-P bond hydrolysis reaction, 5-phospho- $\alpha$-D-ribosyl-1,2-cyclyc phosphate (PRcP) (Figure 1) (He et al., 2011; Hove-Jensen et al., 2011), is not present in 

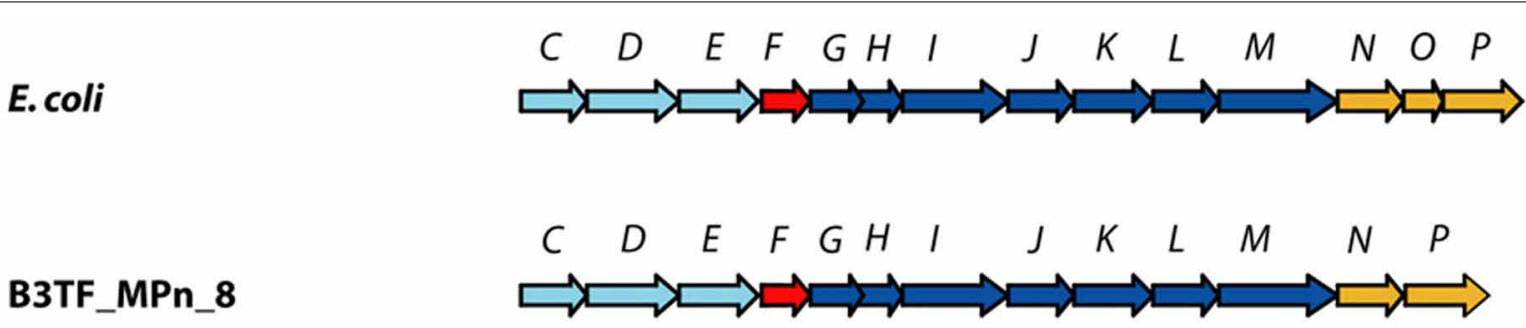

(V. nigripulchritudo ATCC27043)

\section{B3TF_MPn_1 (gamma IMCC1989)}

\author{
B3TF_MPn_2 \\ (Rhodobacterales)
}
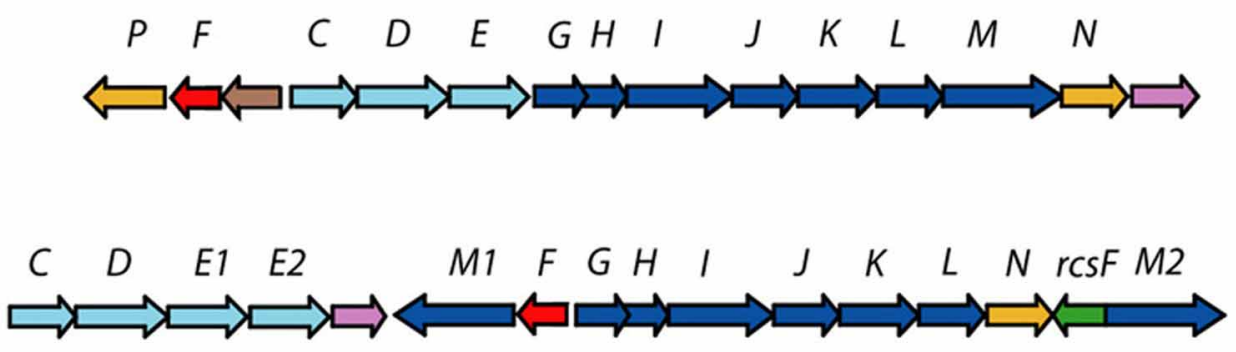

FIGURE 8 | Schematic representation of C-P lyase gene clusters in E. coli and environmental fosmids identified in the MPn utilization functional screen of the B3_TF library. Genes are marked according to their assigned function as follows: putative $A B C$ transporter components (light blue), catalytic components required for MPn degradation (dark blue), regulatory (red) and accessory proteins (orange). New genes are marked as follows: green, $r C S F$ phosphoesterase probably analogous to phnP; brown: putative acyl-CoA N-acetyltransferase; purple: putative transferase.
B3_TF_MPn_2. However, an unrelated protein also belonging to the $2 \mathrm{H}$ phophoesterase superfamily of cyclic nucleotide phosphodiesterases (Mazumder et al., 2002) is encoded in this cluster (green arrow in Figure 8) as well as in other C-P lyase clusters of sequenced microbes which also lack phnP (Huang et al., 2005). Therefore, it is likely that this protein, sometimes referred to as RcsF, plays the same role in MPn degradation as $\mathrm{PhnP}$ by hydrolyzing the cyclic phosphate in $\mathrm{PRcP}$ thus channeling the $\mathrm{P}$ in MPn to primary metabolism.

Another important characteristic of these clusters is that all lack a $p h n O$ gene which encodes a aminoalkylphosphonate $\mathrm{N}$-acetyltransferase that in $E$. coli is required for catabolism and detoxification of 1-aminoalkylphosphonic acids (Errey and Blanchard, 2006; Hove-Jensen et al., 2012). Therefore, we predicted that none of the 3 marine clusters would enable utilization of 1-aminoalkylphosphonates. To test this hypothesis, we analyzed the Pn specificity of E.coli strains expressing each of the three clusters (Table 2) and found that while all of them allow the use of MPn, ethylphosphonate, 3-phosphonpropionate, 2-aminoethylphosphonate, and 3-aminophosphonopropionate as the sole $\mathrm{P}$ source, they were not able to grow on aminomethylphosphonate or 1aminoethyphosphonate, consistent with the lack of phnO.

Finally, several genes encoding proteins of unknown function are found embedded in the new marine C-P lyase clusters and in the clusters of related sequenced marine genomes. These include a second putative phnM-like metal-dependent hydrolase and a second phnE permease component of the $\mathrm{ABC}$ transporter in B3_TF_MPn_2 (phnM1 and phnE2 in Figure 8), a putative acylCoA N-acetyltransferase of the GNAT family in B3_TF_MPn_2 (brown in Figure 8), and a putative transferase of the hexapeptide repeat family in B3_TF_MPn_1 and 2 (purple in Figure 8). Although the exact role of these proteins in Pn utilization remains to be defined, they may mediate the utilization of particular Pn substrates found in the marine environment. Nevertheless, the broad substrate specificity of all three marine clusters implies that the microbes that were enriched after MPn amendment could also be involved in the degradation of other Pns present in the marine environment such as 2-AEPn, found as a side group of glycoproteins and exopolysaccharides and in the polar head group of phosphonolipids of many marine organisms (Horiguchi, 1984), or the recently described MPn esters produced by the abundant marine archaeon Nitrosopumilus maritimus (Metcalf et al., 2012).

No non-C-P lyase MPn utilization pathways were identified in our functional screens. Although we cannot exclude the possibility that other MPn pathways may exist in the library but were not found because of possible expression problems in the heterologous host, the fact that we recovered multiple overlapping C-P lyase clusters from the major taxonomic groups enriched during the MPn-amendment experiment suggests that the C-P lyase pathway was the major metabolic pathway responsible for MPn utilization in this experiment.

\section{DISCUSSION}

One of the major challenges of microbial ecology is to describe, quantify and model the activities of microbes in global biogeochemical cycles. Because the oceans represent $1-4 \%$ of global $\mathrm{CH}_{4}$ emissions, the qualitative and quantitative contributions of microbes to the upper ocean's $\mathrm{CH}_{4}$ cycle is of significant interest. It has been hypothesized that aerobic utilization of MPn 
in P-limited waters could contribute significantly to the upper ocean's $\mathrm{CH}_{4}$ supersaturation (Karl et al., 2008), yet very little is known about the microbes, metabolic pathways and environmental conditions involved. In this study, short term incubation of natural bacterial populations collected in the oligotrophic North Pacific Subtropical Gyre under conditions leading to $\mathrm{CH}_{4}$ accumulation revealed a temporal succession of microbial taxa and metabolic processes. Initially, the addition of Glc $+\mathrm{N}$ led to a large bloom of a population highly similar to sequenced $V$. splendidus strains. Protein encoding transcripts associated with this taxon increased from less than $1 \%$ to more than $42 \%$ of the metatranscriptome uniquely assigned reads in a $12 \mathrm{~h}$ period demonstrating the superior ability of these organisms to respond quickly to elevated nutrients, a typical trait of organisms with a trophic strategy referred to as opportunistic (Polz et al., 2006; Lauro et al., 2009). In contrast to microbes adapted to grow optimally under oligotrophic conditions, opportunistic microbes grow optimally under high nutrient conditions, typically have multiple rRNA operons, maintain elevated numbers of ribosomes during starvation, and possess a wide variety of nutrient sensing and metabolic pathways (Kramer and Singleton, 1992; Flardh and Kjelleberg, 1994; Polz et al., 2006; Lauro et al., 2009). Our transcriptomic data provide an opportunity to analyze in detail the regulatory and metabolic processes underlying such quick response to nutrient enrichment. Addition of Glc $+\mathrm{N}$ led to the elevated representation of transcripts associated with the Glc-specific PTS system that mediates Glc uptake and of those encoding enzymes to synthesize PHAs from acetate, the product of glycolysis. Given that the original concentration of DIP in the seawater was $51 \mathrm{nM}$, the growth elicited by Glc $+\mathrm{N}$ addition $(600 \mu \mathrm{M} \mathrm{C}$ and $16 \mu \mathrm{M} \mathrm{N}$, respectively), is predicted to quickly lead to $\mathrm{P}$ limitation provided all other required trace elements and organic cofactors (i.e., vitamins) are present in excess. Our data clearly show an enrichment of transcripts associated with $\mathrm{P}$ acquisition such as the phosphatespecific $\mathrm{ABC}$ transporter, the alkaline phosphatases $p h o X$ and $p h o A$, as well as $p h o B$ and $p h o R$, the master regulators of the Pho operon. While some of these transcripts appear to originate from other members of the community, the majority of the signal corresponds to $V$. splendidus underscoring the importance of $\mathrm{P}$ acquisition to support its population bloom. In contrast, the metagenomic data from the final community in the Glc $+\mathrm{N}$ microcosm, were $V$. splendidus reads constitute a large fraction of the sample, indicate that this population does not harbor a C-P lyase gene cluster, and thus is presumably not able to use MPn as a P source.

Accumulation of poly- $\beta$-hydroxybutyrate has been previously observed in culture for vibrios grown in the presence of excess glucose (Mårdén et al., 1985; Malmcrona-Friberg et al., 1986). Ovreas et al. (2003) reported that a large-celled V. splendidus population filled with C-rich granules became dominant when a natural marine bacterial community was forced to nutrientlimited growth by adding excess glucose (Ovreas et al., 2003). These authors suggested that the success of the large bacteria in glucose-replete treatments is not a consequence of their superior glucose utilization abilities, but rather of their advantage competing for the limiting nutrient resulting from the combination of a large surface for nutrient uptake and low cellular content of the limiting nutrient made possible thanks to the accumulation of C-rich storage granules. In culture, $V$. splendidus experiences a transition from small coccoid cells in C-limiting cultures, to large cells containing C-rich granules under P-limiting conditions (Lovdal et al., 2008). The large C-rich cells under P-limiting conditions exhibited high alkaline phosphate activity and a measured affinity for orthophosphate approaching the theoretical maximum predicted by diffusion-limited uptake (where every phosphate molecule that enters in contact with the cell surface would be taken up) indicating that the large size did not compromise their ability to compete for limiting $\mathrm{P}$. The very high levels of expression of PHA biosynthetic genes, periplasmic alkaline phosphatases and phosphate $\mathrm{ABC}$-transporter components, particularly the periplasmic phosphate-binding protein PtsS observed in our transcriptomic results, as well as the simultaneous appearance of large size cell populations observed by flow cytometry are consistent with this hypothesis. The ability of $V$. splendidus to use non-limiting organic $\mathrm{C}$ to synthesize PHA and thus augment its cell size without increasing its requirement for $\mathrm{P}$ or $\mathrm{N}$ may provide a competitive advantage for mineral nutrient acquisition under excess $\mathrm{C}$ and explain why it was the minor V. splendidus-like component of the bacterial community the group that dominated the glucose-driven initial community shift in the amendments, instead of the Alteromonadales observed after high molecular weight dissolved organic matter addition (McCarren et al., 2010).

Following the initial fast response to Glc $+\mathrm{N}$ addition observed at $24 \mathrm{~h}$, our transcriptomic results indicated that as the initial bloom progresses, acquisition of other nutrients becomes important. For example, we observed enrichment of transcripts

Table 2 | Phosphonate specificity of MPn clones.

\begin{tabular}{|c|c|c|c|c|c|c|c|c|c|c|c|c|c|}
\hline & no $P$ & MPn & AMPn & 2AEPn & 1AEPn & Epn & PnAc & PnAla & $3 P n P$ & 3APPn & HPt & $\mathbf{P t}$ & $\mathbf{P i}$ \\
\hline CC1FOS & - & - & - & - & - & - & - & - & - & - & - & - & + \\
\hline B3_TF_Mpn_1 & - & + & - & + & - & + & + & + & + & + & - & + & + \\
\hline B3_TF_Mpn_8 & - & + & - & + & - & + & + & - & + & + & - & + & + \\
\hline
\end{tabular}

BW16787 harboring CC1FOS (negative control), B3_TF_Mpn_1, B3_TF_Mpn_2, and B3_TF_Mpn_8, were grown in liquid MOPS glycerol cultures with $0.3 \mathrm{mM}$ of the following P sources: methylphosphonate, MPn; aminomethylphosphonate, AMPn; 2-aminoethylphosphonate, 2AEPn; 1-aminoethylphosphonate, 1AEPn; ethylphosphonate, EPn; phosphonoacetate, PnAc; phosphonoalanine, PnAla; 3-phosphonopropionate, 3PnP; 3-aminopropylphosphonate, 3APPn; hypophosphite, HPt; phosphite, Pt; and phosphate, Pi. Optical density at $600 \mathrm{~nm}$ was used to evaluate growth after 6 days of incubation. 
associated with glycerol-3-phosphate, maltose, and spermidinespecific ABC transporters, as well as the extracellular chitinase and other genes involved in the uptake and metabolism of the resulting $\mathrm{N}$-acetylglucosamine monomers. This ability to access a variety of nutrients is characteristic of opportunistic microbes (Polz et al., 2006; Lauro et al., 2009). Finally, we observed an enrichment of transcripts associated with flagellar biosynthesis, motility, and chemotaxis. The chemotactic response that enables marine bacteria to access and exploit short-lived nutrient patches, is also characteristic of the opportunistic lifestyle (Polz et al., 2006; Stocker et al., 2008).

Once the microbial community was driven into $\mathrm{P}$ starvation after the Glc $+\mathrm{N}$ addition, a second population shift took place in the microcosm amended with MPn characterized by the enrichment in microbes containing C-P lyase gene clusters. While the low abundance of Pn utilization genes is consistent with previous observations for metagenomic samples from this area (Karl et al., 2008; Martinez et al., 2010), the high frequency of C-P lyase-containing microbes observed at the end of the experiment is similar to that previously reported for the surface waters of the Sargasso Sea during the stratified summer months when phosphate concentrations are one to two orders of magnitude lower than in the NPSG (Wu et al., 2000; Cavender-Bares et al., 2001; Martinez et al., 2010). Taken together these results indicate that under conditions of $\mathrm{P}$ limitation, the capacity to compete for available Pn became a critical component shaping the microbial community.

In the Sargasso Sea the majority of the C-P lyase reads were most similar to genes from Candidatus Pelagibacter sp. HTCC7211 (Martinez et al., 2010), a highly abundant member of the SAR11 clade of Alphaproteobacteria adapted to oligotrophic conditions (Stingl et al., 2007). In contrast, the MPn-degrading microbes enriched in our experiment belonged to the Vibrionales and Rhodobacterales orders which were only minor components of the Sargasso Sea signal. The success of these groups under our enrichment conditions is likely to be due to their ability to proliferate quickly in response to Glc additions. Similar to vibrios, members of the Roseobacter clade have an opportunistic lifestyle and harbor an enormous diversity of metabolic activities (Moran et al., 2004, 2007). Given that members of this group have been reported to dominate microbial glucose uptake in nutrient enrichment experiments (Alonso and Pernthaler, 2006) and the genomes of sequenced Rhodobacterales often contain C-P lyase gene clusters [25/32 sequenced genomes (Newton et al., 2010)], it is not surprising that the Rhodobacterales became one of the two dominant groups in our Glc $+\mathrm{N}+\mathrm{MPn}$ experiment.

Three functional C-P lyase clusters were recovered from the metagenomic DNA and we were able to show that they allow growth using various $\mathrm{Pn}$ in addition to MPn as the sole P source. While there were differences in substrate specificity among the three clusters probably mediated in part by the novel uncharacterized proteins present, all of them elicited the utilization of 2-AEPn which is believed to be the most abundant Pn in the marine environment (Horiguchi, 1984) suggesting that the marine microbes they came from could be able to access a variety of Pn compounds as their P source. The importance of the recovered C-P lyase pathways in our experiment was underscored by the high expression ratio of its components in the metagenomic and metatranscriptomic samples. This was not the case for the phosphonatase $p h n W$ and $p h n X$ genes encoding enzymes for 2-AEPn which were highly enriched in the Glc+N microcosm but whose expression was below detection in the metatranscriptomic samples. Their lack of expression despite the observed induction of other $\mathrm{P}$ acquisition genes is consistent with the observation that phosphonatase genes are often induced by their substrate and not by $\mathrm{P}$ starvation as is the case for C-P lyase (Ternan et al., 1998; Ternan and Quinn, 1998; Quinn et al., 2007; White and Metcalf, 2007).

Taken together our results confirm the hypothesis of Karl et al. (2008) that aerobic utilization of MPn by C-P lyase containing microbes can lead to $\mathrm{CH}_{4}$ supersaturation under P-stress conditions. How significant are the taxa and pathways identified in this study to the overall $\mathrm{CH}_{4}$ cycle? Even in the oligotrophic surface waters of the NPSG where the C-P lyase containing groups were not abundant ( $<1 \%$ total cell population), we observed significant $\mathrm{CH}_{4}$ accumulation in response to MPn addition well before any increase in C-P lyase transcript abundance (rRNA or protein-coding genes) was observed. No other pathway capable of producing $\mathrm{CH}_{4}$ from $\mathrm{MPn}$ is known or was recovered in our functional screens. Taken together, these results suggest that even at low relative abundance, the C-P lyase containing organisms can contribute to the $\mathrm{CH}_{4}$ supersaturation if MPn is available. In other oligotrophic regions characterized by low $\mathrm{P}$ such as the Sargasso or the Mediterranean Seas, where the prevalence of C-P lyase genes in oligotrophic microbes is higher and expression of C-P lyase genes has been reported (Feingersch et al., 2010; Martinez et al., 2010), abundant bacterial groups such as SAR11 could contribute significantly to the $\mathrm{CH}_{4}$ supersaturation. In addition, opportunistic C-P lyasecontaining microbes identified in this study are abundant in copiotrophic coastal systems, and exhibit transient blooms under specific conditions. For example, several studies have shown that the abundance of Rhodobacterales increases after phytoplankton blooms and that expression of their phosphonate ABC transporter genes increases under the resulting P-depleted conditions (Tada et al., 2011; Rinta-Kanto et al., 2012; Teeling et al., 2012). Similarly, Vibrios and Alteromonads, also enriched in the final community of the Glc+N+MPn enrichment and sources of the other two identified C-P lyase clusters, also exhibit increased abundance during diatom blooms (Asplund et al., 2011; Tada et al., 2011; Rinta-Kanto et al., 2012). Finally, the abundance of the MPn-degrading copiotrophs might be higher in the nutrient rich particle-associated fraction than in the free-living fraction. For example, bacterial assemblages in marine aggregates do appear distinct from the surrounding free-living bacterioplankton (DeLong et al., 1993; Crump et al., 1999; Eloe et al., 2010; Smith et al., 2013), and Pn have been shown to be preferentially remineralized relative to phosphate esters in sedimenting particles (Benitez-Nelson et al., 2004).

Ultimately, the contribution of MPn utilization to the $\mathrm{CH}_{4} \mathrm{lev}$ els will depend not only on the P-stress levels and abundance of C$\mathrm{P}$ lyase containing microbes, but on the availability of MPn. Until now MPn has only been shown to be synthesized by the abundant marine archaeon Nitrosopumilus maritimus, although genes similar to those involved in MPn biosynthesis in this organism 
are present in the Global Ocean Survey samples including scaffolds of abundant clades such as SAR11 (Metcalf et al., 2012). Although further analyses of MPn abundance and turnover will be required to evaluate the extent to which MPn degradation contributes to the $\mathrm{CH}_{4}$ supersaturation of the oceans, the microbes and processes described here could have a significant impact on our understanding of the $\mathrm{CH}_{4}$ cycle in the sea.

\section{MATERIALS AND METHODS MICROCOSM SETUP AND SAMPLING}

Seawater for the microcosm incubation experiments was collected at Station $1\left(22^{\circ} 30.018^{\prime} \mathrm{N}, 157^{\circ} 30.033^{\prime} \mathrm{W}\right)$ from $75 \mathrm{~m}$ depth at 7:30AM on 7/31/2008 during the Center for Microbial Oceanography: Research and Education (C-MORE) OPEREX cruise. Sampling was conducted using a conductivitytemperature-depth (CTD) rosette sampler aboard the R/V Kilo Moana. CTD and nutrient data were obtained from the HOT program database (http://hahana.soest.hawaii.edu/cmoreDS). Water was transferred to $3 \times 20 \mathrm{~L}$ acid-washed, sample-water rinsed polycarbonate carboys. Carboys were shaded using black fiberglass screen and placed in blue deckboard incubators to achieve a final light level equivalent to 3\% surface irradiance (the in situ light intensity at $75 \mathrm{~m}$ ). The incubator was plumbed with surface seawater to maintain near in situ temperatures. The three microcosms were amended as follows: (B1) unamended control; (B2) $100 \mu \mathrm{M}$ glucose and $16 \mu \mathrm{M}$ nitrate, hereafter referred to as Glc $+\mathrm{N}$; and (B3) $100 \mu \mathrm{M}$ glucose, $16 \mu \mathrm{M}$ nitrate, and $1 \mu \mathrm{M}$ MPn (Sigma) hereafter referred to as Glc $+\mathrm{N}+\mathrm{MPn}$. Microcosm incubations were initiated at $\sim 8: 30 \mathrm{AM}$ and subsamples were taken at $0,3,6,12,24,36$, and $48 \mathrm{~h}$ post addition. For DNA extraction, $10 \mathrm{~L}$ samples were taken at T0 directly from the Niskin bottle and from each of the three microcosms at $48 \mathrm{~h}$ post amendment (TF). Samples were prefiltered though $1.6 \mu \mathrm{m}$ GF/A filters ( $47 \mathrm{~mm}$, Whatman), and collected using a $0.22 \mu \mathrm{m}$ Sterivex filter (Millipore). Three milliliters of lysis buffer $(50 \mathrm{mM}$ Tris- $\mathrm{HCl}, 40 \mathrm{mM}$ EDTA, $0.75 \mathrm{M}$ sucrose, $\mathrm{pH}$ 8.3) were added to each filter unit which was then frozen at $-20^{\circ} \mathrm{C}$. For RNA extraction $1 \mathrm{~L}$ subsamples were prefiltered through $1.6 \mu \mathrm{m}$ GF/A filters ( $47 \mathrm{~mm}$, Whatman), and microbial biomass was collected onto $0.22 \mu \mathrm{m}$ Durapore filters ( $25 \mathrm{~mm}$, Millipore). Filters were immediately transferred to microcentrifuge tubes containing $300 \mu \mathrm{l}$ RNAlater (Ambion) and frozen at $-80^{\circ} \mathrm{C}$ until extraction.

\section{$\mathrm{CH}_{4}$ MEASUREMENTS}

Dissolved $\mathrm{CH}_{4}$ concentrations were determined by gas chromatography as previously described (Tilbrook and Karl, 1995). Briefly, water samples were collected in $250 \mathrm{ml}$ glass BOD-type bottles which were filled from the bottom to three times overflowing, aspirated to just below the neck and poisoned with $200 \mu \mathrm{l}$ saturated mercuric chloride solution. The glass stoppers were replaced after light greasing (Apiezon), secured with polyethylene tape, and stored in the dark at ambient room temperature until analysis. $\mathrm{CH}_{4}$ concentrations were determined onboard the ship using purge and trap extraction followed by $\mathrm{CH}_{4}$ quantification using a GC-Flame Ionization Detector (Agilent 7890A). Samples were transferred from the BOD bottle to a purge chamber under positive pressure using helium $(80 \mathrm{ml} / \mathrm{min})$ and sparged in a $250 \mathrm{~mL}$ glass purge chamber for $10 \mathrm{~min}$. The stripped gases were passed through a nafion drier (Perma Pure LLC), and drierite (VWR) before being cold-trapped on a sample loop containing Porapak Q 80/100 (Sigma-Aldrich) and maintained at $-80^{\circ} \mathrm{C}$ using liquid nitrogen. The sample loop was then heated to $90^{\circ} \mathrm{C}$ and the trapped $\mathrm{CH}_{4}$ injected onto a $30 \mathrm{~m} \times 0.32 \mathrm{~mm}$ GS-CarbonPLOT analytical capillary column (J\&W Scientific) maintained at a temperature of $35^{\circ} \mathrm{C}$. The FID was calibrated for $\mathrm{CH}_{4}$ using serial dilutions of a $10 \mathrm{ppmv}$ primary standard in nitrogen (Scott-Marin). Data acquisition was performed using ChemStation software version B.03.01.

\section{FLOW CYTOMETRY}

At each time point, $1 \mathrm{ml}$ of seawater was preserved with glutaraldehyde ( $0.125 \%$ final concentration), frozen in liquid nitrogen, and stored at $-80^{\circ} \mathrm{C}$ for subsequent analysis. Cells were identified after SYBR Green staining (Life Technologies) using an Influx flow cytometer (Becton Dickinson) as previously described (Marie et al., 1997). Data were analyzed using FlowJo software. Cell counts reported are the average of 3 technical replicates.

\section{NUCLEIC ACID EXTRACTION AND SEQUENCING}

DNA extraction for sequencing and fosmid library construction was performed as previously described (Frias-Lopez et al., 2008). For community RNA extractions, filters were thawed on ice, RNAlater was carefully removed and RNA was extracted using the mirVana RNA isolation kit (Ambion, Austin, TX) as previously described (Shi et al., 2009). Following RNA extraction, gDNA was removed by digestion with Turbo-DNA Free DNAse (Ambion, Austin, TX), and total RNA was concentrated using the RNeasy MinElute Cleanup kit (Qiagen, Valencia, CA).

RNA amplification and cDNA synthesis were performed as described previously (McCarren et al., 2010; Shi et al., 2011). In brief, roughly 10-20 ng of total RNA were amplified using MessageAmp II Bacteria kit (Ambion) and T7Bpm $\mathrm{IdT}_{16} \mathrm{VN}$, an oligo(dT) primer containing a promoter sequence for T7 RNA polymerase and a BpmI recognition site. CDNA was synthesized from the amplified RNA using Superscript III (Invitrogen) and random hexamers for first-strand complementary DNA synthesis, and the SuperScript Double Stranded cDNA Synthesis kit (Invitrogen) for second-strand synthesis. The resulting cDNA was purified using the Qiaquick PCR purification kit (Qiagen), digested with BpmI to remove poly(A) tails and used directly for pyrosequencing. gDNA and cDNA single-stranded libraries were prepared and sequenced using standard GS FLX protocols (454 Life Sciences, Roche) in a Roche Genome Sequencer FLX (Roche Applied Science, Indianapolis, IN).

\section{BIOINFORMATIC ANALYSES}

Reads matching rRNA genes in the gDNA and cDNA databases were identified using BLASTN against a database of 5S, 16S, 18S, 23S, and 28S rRNA sequences derived from the SILVA database (http://www.arb-silva.de) and microbial genomes (Ottesen et al., 2011). Reads aligning with bit scores $>50$ were parsed out as rRNA sequences and assigned to taxonomic groups according to NCBI taxonomy based on their best match in the SILVA LSU and 
SSU database. cDNA reads corresponding to known small non coding RNA (sRNA) were identified and mapped to the corresponding sRNA family by BLASTN comparison against the Rfam 10.1 database (http://rfam.sanger.ac.uk) using a bit score cut off of 50 .

Non-rRNA, non-sRNA reads were assigned to a single reference gene in the NCBI-nr database (as of September 26, 2011) using BLASTX and a bit score cut-off of 50 as previously described (Ottesen et al., 2011). Reads were assigned to the NCBI taxonomy based on the top hit of the BLASTX comparison against the NCBI-nr database. For this analysis, only reads that could be uniquely assigned to a single taxonomic id were considered. Representation of individual taxa was calculated by normalizing the taxon counts to the number of reads in each library with significant matches in NCBI-nr.

For functional comparison across databases, non-rRNA, nonsRNA sequences were assigned to functional categories based on the KEGG database. The top reference gene(s) in the May 30, 2010 version of the KEGG database matching each read (bit score $>50$ ) was used for annotation. For reads matching multiple reference genes with equal bit score, all top hits were retained with its representation scaled proportionally to the number of top hits (Stewart et al., 2011). Ortholog counts for each sample were normalized to the total number of non-rRNA, non-sRNA sequences with significant matches to the KEGG database. KEGG ortholog (KO) abundances were compared across libraries using the AC Test (Audic and Claverie, 1997) and a false discovery rate correction for multiple comparisons (Benjamini and Hochberg, 1995) as previously described (Ottesen et al., 2011). Only KO with FDR $<0.05$ were considered significant in this analysis.

KEGG pathway counts were generated based on the total number of sequences assigned to $\mathrm{KO}$ annotations within that pathway. As described above for KO, pathway representation was calculated normalizing pathway counts to the total number of non-rRNA, non-sRNA sequences with significant matches to the KEGG database. Because some of the most abundantly expressed orthologs in the amendments are involved in processes not included in the standard KEGG pathways we modified the KEGG pathway database to better capture the observed changes by annotating three relevant and well-characterized microbial pathways: alkylphosphonate metabolism, phosphate metabolism, and polyhydroxyalkanoate biosynthesis. Only KEGG orthologs with assigned KO numbers and clear genetic or biochemical evidence to support their assignment were included in each of these pathways (see list in Table S4). Read counts across KEGG pathways were used to cluster non-rRNA, non-sRNA cDNA datasets based on shared gene content using GenePattern software (http:// genepattern.broadinstitute.org) (Reich et al., 2006). Samples were clustered using hierarchical clustering based on pairwise averagelinkage method with Pearson correlation coefficients as the distance measure. Only pathways representing $>1 \%$ of total $\mathrm{KO}$ reads in at least one time point were included in the cluster analysis.

Abundance of Pn-degrading microbes in our metagenomic libraries was assessed as previously described (Martinez et al., 2010). Briefly, predicted protein sequences of known phn genes and E. coli RecA and GyrB as single copy reference were used as query to interrogate available databases using NCBI TBLASTN and a bit score cut off value of 50 . Gene counts were size normalized using the query protein length. The percentage of microbes containing each gene was calculated assuming that $r e c A$ is present in single copy in every microbial genome (Howard et al., 2008; Reisch et al., 2008). For each identified C-P lyase gene, putative taxonomic affiliation was assigned based on its top scoring hit in the NCBI-nr databse.

The expression of predicted proteins in the fosmids identified in MPn utilization functional screens was determined as follows. Predicted protein sequences were used to query the $48 \mathrm{~h}$ metagenomic and metatranscriptomic databases from the Glc $+\mathrm{N}+\mathrm{MPn}$ enrichment (B3) using TBLASTN. The number of reads matching each predicted protein (bit score $>50, \%$ identity $>95$ ) was normalized to the total number of reads in the library. Expression ratio was expressed as the ratio (non-rRNA non-sRNA reads per gene/total non-rRNA non-sRNA reads)/(gDNA reads matching gene/total gDNA reads).

\section{FUNCTIONAL SCREENING}

A large-insert metagenomic DNA library was constructed from the Glc $+\mathrm{N}+\mathrm{MPn}$ final DNA sample (B3_TF) using fosmid vector pCC1FOS (Epicentre) as previously described (DeLong et al., 2006). The resulting phage lysate was used to infect $E$. coli EPI300. Approximately 47,000 fosmid-containing colonies $(\sim 1.4 \mathrm{~Gb}$ metagenomic DNA $)$ were pooled and used to prepare fosmid DNA by alkaline lysis followed by cesium chloride ultracentrifugation (Sambrook et al., 1989). The resulting B3_TF metagenomic library was screened for MPn utilization as previously described (Martinez et al., 2010). MPn positive clones were de-replicated by restriction analyses and sequenced using transposon mutagenesis as described (Martinez et al., 2007). The complete DNA sequence was assembled using Sequencher v. 4.10 (Gene Codes Corporation, Ann Arbor, MI) and annotated with FGENESB (Softberry) and BlastP (NCBI). Pn specificity was evaluated in microtiter plate liquid cultures (MOPS glycerol medium with $0.1 \mathrm{mM}$ of the indicated P source) as described in (Martinez et al., 2010) except that culture absorbance $(600 \mathrm{~nm})$ was used to measure growth.

\section{GenBank ACCESSION NUMBERS}

Fosmid sequences have been submitted to GenBank and are available under accession numbers KF742554-KF742556. The 454 metagenomic and metatranscriptomic data had been deposited with the Short Reads Archive (NCBI) under Accession No. SRP030766.

\section{ACKNOWLEDGMENTS}

We thank the captain and crew of the R/V Kilo Moana, the C-MORE OPEREX chief scientist, Zbigniew Kolber, and the OPEREX and HOT teams for support and ancillary measurements; Rachel Barry and Tsultrim Palden for pyrosequencing; Tsultrim Palden for assistance with fosmid sequencing. We also thank John Eppley and Elizabeth Ottesen for assistance with informatics, and Julie Miller and Allison Coe for their help with FACS analyses. This work was supported by grants from the Gordon and Betty Moore Foundation (David M. Karl and Edward 
F. DeLong) and NSF grant EF0424599 (David M. Karl and Edward F. DeLong). This work is a contribution of the Center for Microbial Oceanography: Research and Education (C-MORE).

\section{SUPPLEMENTARY MATERIAL}

The Supplementary Material for this article can be found online at: http://www.frontiersin.org/journal/10.3389/ fmicb.2013.00340/abstract

\section{REFERENCES}

Alonso, C., and Pernthaler, J. (2006). Roseobacter and SAR11 dominate microbial glucose uptake in coastal North Sea waters. Environ. Microbiol. 8, 2022-2030. doi: 10.1111/j.1462-2920.2006.01082.x

Asplund, M. E., Rehnstam-Holm, A. S., Atnur, V., Raghunath, P., Saravanan, V., Harnstrom, K., et al. (2011). Water column dynamics of Vibrio in relation to phytoplankton community composition and environmental conditions in a tropical coastal area. Environ. Microbiol. 13, 2738-2751. doi: 10.1111/j.14622920.2011.02545.x

Audic, S., and Claverie, J. M. (1997). The significance of digital gene expression profiles. Genome Res. 7, 986-995.

Babitzke, P., and Romeo, T. (2007). CsrB sRNA family: sequestration of RNA-binding regulatory proteins. Curr. Opin. Microbiol. 10, 156-163. doi: 10.1016/j.mib.2007.03.007

Benitez-Nelson, C. R., O’neill, L., Kolowith, L. C., Pellecia, P., and Thunell, R. (2004). Phosphonates and particulate organic phosphorus cycling in an anoxic marine basin. Limnol. Oceanogr. 49, 1593-1604. doi: 10.4319/lo.2004.49. 5.1593

Benjamini, Y., and Hochberg, Y. (1995). Controlling the false discovery rate: a practical and powerful approach to multiple testing. J. R. Statist. Soc. B Methodol. 57, 289-300.

Cavender-Bares, K. K., Karl, D. M., and Chisholm, S. W. (2001). Nutrient gradients in the western North Atlantic Ocean: relationship to microbial community structure and comparison to patterns in the Pacific Ocean. Deep Sea Res. I Oceanogr. Res. Papers 48, 2373-2395. doi: 10.1016/S0967-0637(01) 00027-9

Clark, L. L., Ingall, E. D., and Benner, R. (1999). Marine organic phosphorus cycling: novel insights from nuclear magnetic resonance. Am. J. Sci. 2999, 724-737. doi: 10.2475/ajs.299.7-9.724

Coleman, M. L., and Chisholm, S. W. (2010). Ecosystem-specific selection pressures revealed through comparative population genomics. Proc. Natl. Acad. Sci. U.S.A. 107, 18634-18639. doi: 10.1073/pnas.1009480107

Cordaro, C. (1976). Genetics of the bacterial phosphoenolpyruvate: glycose phosphotransferase system. Annu. Rev. Genet. 10, 341-359. doi: 10.1146/annurev.ge.10.120176.002013

Crump, B. C., Armbrust, E. V., and Baross, J. A. (1999). Phylogenetic analysis of particle-attached and free-living bacterial communities in the Columbia river, its estuary, and the adjacent coastal ocean. Appl. Environ. Microbiol. 65, 3192-3204.

Daughton, C. G., Cook, A. M., and Alexander, M. (1979). Biodegradation of phosphonate toxicants yields methane or ethane on cleavage of the C-P bond. FEMS Microbiol. Lett. 5, 91-93. doi: 10.1111/j.1574-6968.1979. tb03254.x

DeLong, E. F., Franks, D. G., and Alldredge, A. L. (1993). Phylogenetic diversity of aggregate-attached vs. free-living marine bacterial assemblages. Limnol. Oceanogr. 38, 924-934. doi: 10.4319/lo.1993.38.5.0924

DeLong, E. F., Preston, C. M., Mincer, T., Rich, V., Hallam, S. J., Frigaard, N.-U., et al. (2006). Community genomics among stratified microbial assemblages in the ocean's interior. Science 311, 496-503. doi: 10.1126/science. 1120250

Duhamel, S., Dyhrman, S. T., and Karl, D. M. (2010). Alkaline phosphatase activity and regulation in the North Pacific Subtropical Gyre. Limnol. Oceanogr. 55, 1414-1425. doi: 10.4319/lo.2010.55.3.1414

Dunfield, P. F., Yuryev, A., Senin, P., Smirnova, A. V., Stott, M. B., Hou, S., et al. (2007). Methane oxidation by an extremely acidophilic bacterium of the phylum Verrucomicrobia. Nature 450, 879-882. doi: 10.1038/nature 06411
Dyhrman, S. T., Ammerman, J. W., and Van Mooy, B. A. S. (2007). Microbes and the marine phosphorus cycle. Oceanography 20, 110-116. doi: 10.5670/oceanog.2007.54

Dyhrman, S. T., Chappell, P. D., Haley, S. T., Moffett, J. W., Orchard, E. D., Waterbury, J. B., et al. (2006). Phosphonate utilization by the globally important marine diazotroph Trichodesmium. Nature 439, 68-71. doi: 10.1038 /nature04203

Dyhrman, S. T., and Haley, S. T. (2006). Phosphorus scavenging in the unicellular marine diazotroph Crocosphaera watsonii. Appl. Environ. Microbiol. 72, 1452-1458. doi: 10.1128/AEM.72.2.1452-1458.2006

Eloe, E. A., Shulse, C. N., Fadrosh, D. W., Wiliamson, S. J., Allen, E. E., and Barlett, D. H. (2010). Compositional differences in particle-associated and free-living microbial assemblages from an extreme deep-ocean environment. Environ. Microbiol. Rep. 3, 449-458. doi: 10.1111/j.1758-2229.2010. 00223.x

Errey, J. C., and Blanchard, J. S. (2006). Functional annotation and kinetic characterization of PhnO from Salmonella enterica. Biochemistry 45, 3033-3039. doi: 10.1021/bi052297p

Feingersch, R., Suzuki, M. T., Shmoish, M., Sharon, I., Sabehi, G., Partensky, F., et al. (2010). Microbial community genomics in eastern Mediterranean Sea surface waters. ISME J. 4, 78-87. doi: 10.1038/ismej.2009.92

Flardh, K., and Kjelleberg, S. (1994). Glucose upshift of carbon-starved marine Vibrio sp. strain S14 causes amino acid starvation and induction of the stringent response. J. Bacteriol. 176, 5897-5903.

Frias-Lopez, J., Shi, Y., Tyson, G. W., Coleman, M. L., Schuster, S. C., Chisholm, S. W., et al. (2008). Microbial community gene expression in ocean surface waters. Proc. Natl. Acad. Sci. U.S.A. 105, 3805-3810. doi: 10.1073/pnas. 0708897105

Gardner, P. P., Daub, J., Tate, J. G., Nawrocki, E. P., Kolbe, D. L., Lindgreen, S., et al. (2009). Rfam: updates to the RNA families database. Nucleic Acids Res. 37, D136-140. doi: 10.1093/nar/gkn766

Gilbert, J. A., Thomas, S., Cooley, N. A., Kulakova, A., Field, D., Booth, T., et al. (2009). Potential for phosphonoacetate utilization by marine bacteria in temperate coastal waters. Environ. Microbiol. 11, 111-125. doi: 10.1111/j.14622920.2008.01745.x

Hanson, R. S., and Hanson, T. E. (1996). Methanotrophic bacteria. Microbiol. Rev. $60,439-471$.

Havelsrud, O. E., Haverkamp, T. H., Kristensen, T., Jakobsen, K. S., and Rike, A. G. (2011). A metagenomic study of methanotrophic microorganisms in Coal Oil Point seep sediments. BMC Microbiol. 11:221. doi: 10.1186/1471-2180-11-221

He, S. M., Wathier, M., Podzelinska, K., Wong, M., McSorley, F. R., Asfaw, A., et al. (2011). Structure and mechanism of PhnP, a phosphodiesterase of the carbon-phosphorus lyase pathway. Biochemistry 50, 8603-8615. doi: 10.1021/ bi2005398

Horiguchi, M. (1984). "Occurrence, identification and properties of phosphonic and phosphinic acids," in The Biochemistry of Natural C-P Compounds, eds T. Hoti, M. Horiguchi, and A. Hayashi (Kyoto: Maruzen), 24-52.

Hove-Jensen, B., McSorley, F. R., and Zechel, D. L. (2011). Physiological role of phnP-specified phosphoribosyl cyclic phosphodiesterase in catabolism of organophosphonic acids by the carbon-phosphorus lyase pathway. J. Am. Chem. Soc. 133, 3617-3624. doi: 10.1021/ja1102713

Hove-Jensen, B., McSorley, F. R., and Zechel, D. L. (2012). Catabolism and detoxification of 1-aminoalkylphosphonic acids: $\mathrm{N}$-acetylation by the phnO gene product. PLoS ONE 7:e46416. doi: 10.1371/journal.pone.0046416

Hove-Jensen, B., Rosenkrantz, T. J., Haldimann, A., and Wanner, B. L. (2003). Escherichia coli phnN, encoding ribose 1,5-bisphosphokinase activity (phosphoribosyl diphosphate forming): dual role in phosphonate degradation and NAD biosynthesis pathways. J. Bacteriol. 185, 2793-2801. doi: 10.1128/JB.185.9.27932801.2003

Hove-Jensen, B., Rosenkrantz, T. J., Zechel, D. L., and Willemoes, M. (2010). Accumulation of intermediates of the carbon-phosphorus lyase pathway for phosphonate degradation in phn mutants of Escherichia coli. J. Bacteriol. 192, 370-374. doi: 10.1128/JB.01131-09

Howard, E. C., Sun, S., Biers, E. J., and Moran, M. A. (2008). Abundant and diverse bacteria involved in DMSP degradation in marine surface waters. Environ. Microbiol. 10, 2397-2410. doi: 10.1111/j.1462-2920.2008.01665.x

Huang, J., Su, Z., and Xu, Y. (2005). The evolution of microbial phosphonate degradative pathways. J. Mol. Evol. 61, 682-690. doi: 10.1007/s00239-0040349-4 
Jang, Y., Oh, H. M., Kim, H., Kang, I., and Cho, J. C. (2011). Genome sequence of strain IMCC1989, a novel member of the marine gammaproteobacteria. J. Bacteriol. 193, 3672-3673. doi: 10.1128/JB.05202-11

Kamat, S. S., Williams, H. J., Dangott, L. J., Chakrabarti, M., and Raushel, F. M. (2013). The catalytic mechanism for aerobic formation of methane by bacteria. Nature 497, 132-136. doi: 10.1038/nature12061

Kamat, S. S., Williams, H. J., and Raushel, F. M. (2011). Intermediates in the transformation of phosphonates to phosphate by bacteria. Nature 480, 570-573. doi: 10.1038 /nature 10622

Karl, D. M., Beversdorf, L., Björkman, K. M., Church, M. J., Martinez, A., and DeLong, E. F. (2008). Aerobic production of methane in the sea. Nat. Geosci. 1, 473-478. doi: 10.1038/ngeo234

Kittredge, J. S., and Roberts, E. (1969). A carbon-phosphorus bond in nature. Science 164, 37-42. doi: 10.1126/science.164.3875.37

Kolowith, L. C., Ingall, E. D., and Benner, R. (2001). Composition and cycling of marine organic phosphorus. Limnol. Oceanogr. 46, 309-320. doi: 10.4319/lo.2001.46.2.0309

Kramer, J. G., and Singleton, F. L. (1992). Variations in rRNA content of marine Vibrio spp. during starvation-survival and recovery. Appl. Environ. Microbiol. 58, 201-207.

Lamontagne, R. A., Swinnerton, J. W., Linnenbom, V. J., and Smith, W. D. (1973). Methane concentrations in various marine environments. J. Geophys. Res. 78, 5317-5324. doi: 10.1029/JC078i024p05317

Lauro, F. M., McDougald, D., Thomas, T., Williams, T. J., Egan, S., Rice, S., et al. (2009). The genomic basis of trophic strategy in marine bacteria. Proc. Natl. Acad. Sci. U.S.A. 106, 15527-15533. doi: 10.1073/pnas.0903507106

Lee, P. A., Tullman-Ercek, D., and Georgiou, G. (2006). The bacterial twinarginine translocation pathway. Annu. Rev. Microbiol. 60, 373-395. doi: 10.1146/annurev.micro.60.080805.142212

Lovdal, T., Skjoldal, E. F., Heldal, M., Norland, S., and Thingstad, T. F. (2008). Changes in morphology and elemental composition of Vibrio splendidus along a gradient from carbon-limited to phosphate-limited growth. Microb. Ecol. 55, 152-161. doi: 10.1007/s00248-007-9262-X

Malmcrona-Friberg, K., Tunlid, A., Mårdén, P., Kjelleberg, S., and Odham, G. (1986). Chemical changes in cell envelope and poly- $\beta$-hydroxybutyrate during short term starvation of a marine bacterial isolate. Arch. Microbiol. 144, 340-345. doi: 10.1007/BF00409882

Mårdén, P., Tunlid, A., Malmcrona-Friberg, K., Odham, G., and Kjelleberg, S. (1985). Physiological and morphological changes during short term starvation of marine bacterial isolates. Arch. Microbiol. 142, 326-332. doi: 10.1007/BF00491898

Marie, D., Partensky, F., Jacquet, S., and Vaulot, D. (1997). Enumeration and cell cycle analysis of natural populations of marine picoplankton by flow cytometry using the nucleic acid stain SYBR Green I. Appl. Environ. Microbiol. 63, 186-193.

Martinez, A., Bradley, A. S., Waldbauer, J. R., Summons, R. E., and DeLong, E. F. (2007). Proteorhodopsin photosystem gene expression enables photophosphorylation in a heterologous host. Proc. Natl. Acad. Sci. U.S.A. 104, 5590-5595. doi: 10.1073/pnas.0611470104

Martinez, A., Tyson, G. W., and DeLong, E. F. (2010). Widespread known and novel phosphonate utilization pathways in marine bacteria revealed by functional screening and metagenomic analyses. Environ. Microbiol. 12, 222-238. doi: 10.1111/j.1462-2920.2009.02062.x

Martiny, A. C., Coleman, M. L., and Chisholm, S. W. (2006). Phosphate acquisition genes in Prochlorococcus ecotypes: evidence for genome-wide adaptation. Proc. Natl. Acad. Sci. U.S.A. 103, 12552-12557. doi: 10.1073/pnas.0601301103

Mazumder, R., Iyer, L. M., Vasudevan, S., and Aravind, L. (2002). Detection of novel members, structure-function analysis and evolutionary classification of the $2 \mathrm{H}$ phosphoesterase superfamily. Nucleic Acids Res. 30, 5229-5243. doi: 10.1093/nar/gkf645

McCarren, J., Becker, J. W., Repeta, D. J., Shi, Y., Young, C. R., Malmstrom, R. R., et al. (2010). Microbial community transcriptomes reveal microbes and metabolic pathways associated with dissolved organic matter turnover in the sea. Proc. Natl. Acad. Sci. U.S.A. 107, 16420-16427. doi: 10.1073/pnas.1010732107

Metcalf, W. W., Griffin, B. M., Cicchillo, R. M., Gao, J., Janga, S. C., Cooke, H. A., et al. (2012). Synthesis of methylphosphonic acid by marine microbes: a source for methane in the aerobic ocean. Science 337, 1104-1107. doi: $10.1126 /$ science. 1219875
Metcalf, W. W., and Wanner, B. L. (1991). Involvement of the Escherichia coli phn ( $p s i D)$ gene cluster in assimilation of phosphorus in the form of phosphonates, phosphite, Pi esters, and Pi. J. Bacteriol. 173, 587-600.

Metcalf, W. W., and Wanner, B. L. (1993a). Evidence for a fourteen-gene, phnC to phnP locus for phosphonate metabolism in Escherichia coli. Gene 129, 27-32. doi: 10.1016/0378-1119(93)90692-V

Metcalf, W. W., and Wanner, B. L. (1993b). Mutational analysis of an Escherichia coli fourteen-gene operon for phosphonate degradation, using TnphoA' elements. J. Bacteriol. 175, 3430-3442.

Monds, R. D., Newell, P. D., Schwartzman, J. A., and O’Toole, G. A. (2006). Conservation of the Pho regulon in Pseudomonas fluorescens Pf0-1. Appl. Environ. Microbiol. 72, 1910-1924. doi: 10.1128/AEM.72.3.1910-1924.2006

Moran, M. A., Belas, R., Schell, M. A., Gonzalez, J. M., Sun, F., Sun, S., et al. (2007). Ecological genomics of marine Roseobacters. Appl. Environ. Microbiol. 73, 4559-4569. doi: 10.1128/AEM.02580-06

Moran, M. A., Buchan, A., Gonzalez, J. M., Heidelberg, J. F., Whitman, W. B., Kiene, R. P., et al. (2004). Genome sequence of Silicibacter pomeroyi reveals adaptations to the marine environment. Nature 432, 910-913. doi: 10.1038/nature 03170

Moreno-Vivian, C., Cabello, P., Martinez-Luque, M., Blasco, R., and Castillo, F. (1999). Prokaryotic nitrate reduction: molecular properties and functional distinction among bacterial nitrate reductases. J. Bacteriol. 181, 6573-6584.

Neufeld, J. D., Schafer, H., Cox, M. J., Boden, R., McDonald, I. R., and Murrell, J. C. (2007). Stable-isotope probing implicates Methylophaga spp and novel Gammaproteobacteria in marine methanol and methylamine metabolism. ISME J. 1, 480-491. doi: 10.1038/ismej.2007.65

Newton, R. J., Griffin, L. E., Bowles, K. M., Meile, C., Gifford, S., Givens, C. E., et al. (2010). Genome characteristics of a generalist marine bacterial lineage. ISME J. 4, 784-798. doi: 10.1038/ismej.2009.150

Ottesen, E. A., Marin, R. I., Preston, C. M., Young, C. R., Ryan, J. P., Scholin, C. A., et al. (2011). Metatranscriptomic analysis of autonomously collected and preserved marine bacterioplankton. ISME J. 5, 1881-1895. doi: 10.1038/ismej.2011.70

Ovreas, L., Bourne, D., Sandaa, R. A., Casamayor, E. O., Benlloch, S., Goddard, V., et al. (2003). Response of bacterial and viral communities to nutrient manipulations in seawater mesocosms. Aquat. Microb. Ecol. 31, 109-121. doi: 10.3354/ame031109

Ploug, H., Buchholz-Cleven, B. E., and Jorgensen, B. B. (1997). Anoxic aggregates - an ephemeral phenomenon in the pelagic environment? Aquat. Microb. Ecol. 13, 285-294. doi: 10.3354/ame013285

Polz, M. F., Hunt, D. E., Preheim, S. P., and Weinreich, D. M. (2006). Patterns and mechanisms of genetic and phenotypic differentiation in marine microbes. Philos. Trans. R. Soc. Lond. B. Biol. Sci. 361, 2009-2021. doi: 10.1098/rstb.2006.1928

Quinn, J. P., Kulakova, A. N., Cooley, N. A., and McGrath, J. W. (2007). New ways to break an old bond: the bacterial carbon-phosphorus hydrolases and their role in biogeochemical phosphorus cycling. Environ. Microbiol. 9, 2392-2400. doi: 10.1111/j.1462-2920.2007.01397.x

Reeburgh, W. S. (2007). Oceanic methane biogeochemistry. Chem. Rev. 107, 486-513. doi: 10.1021/cr050362v

Rehm, B. H., and Steinbuchel, A. (1999). Biochemical and genetic analysis of PHA synthases and other proteins required for PHA synthesis. Int. J. Biol. Macromol. 25, 3-19. doi: 10.1016/S0141-8130(99)00010-0

Reich, M., Liefeld, T., Gould, J., Lerner, J., Tamayo, P., and Mesirov, J. P. (2006). GenePattern 2.0. Nat. Genet. 38, 500-501. doi: 10.1038/ng0506-500

Reisch, C. R., Moran, M. A., and Whitman, W. B. (2008). Dimethylsulfoniopropionate-dependent demethylase (DmdA) from Pelagibacter ubique and Silicibacter pomeroyi. J. Bacteriol. 190, 8018-8024. doi: 10.1128/JB.00770-08

Rinta-Kanto, J. M., Sun, S., Sharma, S., Kiene, R. P., and Moran, M. A. (2012). Bacterial community transcription patterns during a marine phytoplankton bloom. Environ. Microbiol. 14, 228-239. doi: 10.1111/j.1462-2920.2011. 02602.x

Romeo, T., Vakulskas, C. A., and Babitzke, P. (2013). Post-transcriptional regulation on a global scale: form and function of Csr/Rsm systems. Environ. Microbiol. 15, 313-324. doi: 10.1111/j.1462-2920.2012.02794.x

Rudd, J. W. M., and Taylor, C. D. (1980). Methane cycling in aquatic environments. Adv. Aquat. Microbiol. 2, 77-150. 
Sambrook, J., Fritsch, E. F., and Maniatis, T. (1989). Molecular Cloning: a Laboratory Manual. Cold Spring Harbor, NY: Cold Spring Harbor Laboratory Press.

Scanlan, D. J., Mann, N. H., and Carr, N. G. (1993). The response of the picoplanktonic marine cyanobacterium Synechococcus species WH7803 to phosphate starvation involves a protein homologous to the periplasmic phosphate-binding protein of Escherichia coli. Mol. Microbiol. 10, 181-191. doi: 10.1111/j.13652958.1993.tb00914.x

Sebastian, M., and Ammerman, J. W. (2009). The alkaline phosphatase PhoX is more widely distributed in marine bacteria than the classical PhoA. ISME J. 3, 563-572. doi: 10.1038/ismej.2009.10

Shi, T., Ilikchyan, I., Rabouille, S., and Zehr, J. P. (2010). Genome-wide analysis of diel gene expression in the unicellular $\mathrm{N}_{2}$-fixing cyanobacterium Crocosphaera watsonii WH 8501. ISME J. 4, 621-632. doi: 10.1038/ismej.2009.148

Shi, Y., Tyson, G. W., and DeLong, E. F. (2009). Metatranscriptomics reveals unique microbial small RNAs in the ocean's water column. Nature 459, 266-269. doi: 10.1038/nature08055

Shi, Y., Tyson, G. W., Eppley, J. M., and DeLong, E. F. (2011). Integrated metatranscriptomic and metagenomic analyses of stratified microbial assemblages in the open ocean. ISME J. 5, 999-1013. doi: 10.1038/ismej.2010.189

Smith, M. W., Zeigler Allen, L., Allen, A. E., Herfort, L., and Simon, H. M. (2013). Contrasting genomic properties of free-living and particle-attached microbial assemblages within a coastal ecosystem. Front. Microbiol. 4:120. doi: 10.3389/fmicb.2013.00120

Stewart, F. J., Ulloa, O., and DeLong, E. F. (2011). Microbial metatranscriptomics in a permanent marine oxygen minimum zone. Environ. Microbiol. 14, 23-40. doi: $10.1111 / j .1462-2920.2010 .02400 . x$

Stingl, U., Tripp, H. J., and Giovannoni, S. J. (2007). Improvements of highthroughput culturing yielded novel SAR11 strains and other abundant marine bacteria from the Oregon coast and the Bermuda Atlantic Time Series study site. ISME J. 1, 361-371. doi: 10.1038/ismej.2007.49

Stocker, R. (2012). Marine microbes see a sea of gradients. Science 338, 628-633. doi: 10.1126/science. 1208929

Stocker, R., Seymour, J. R., Samadani, A., Hunt, D. E., and Polz, M. F. (2008). Rapid chemotactic response enables marine bacteria to exploit ephemeral microscale nutrient patches. Proc. Natl. Acad. Sci. U.S.A. 105, 4209-4214. doi: 10.1073/pnas.0709765105

Tada, Y., Taniguchi, A., Nagao, I., Miki, T., Uematsu, M., Tsuda, A., et al. (2011). Differing growth responses of major phylogenetic groups of marine bacteria to natural phytoplankton blooms in the western North Pacific Ocean. Appl. Environ. Microbiol. 77, 4055-4065. doi: 10.1128/AEM. 02952-10

Teeling, H., Fuchs, B. M., Becher, D., Klockow, C., Gardebrecht, A., Bennke, C. M., et al. (2012). Substrate-controlled succession of marine bacterioplankton populations induced by a phytoplankton bloom. Science 336, 608-611. doi: $10.1126 /$ science. 1218344

Ternan, N. G., McGrath, J. W., McMullan, G., and Quinn, J. P. (1998). Review: organophosphonates: occurence, synthesis and biodegradation. World J. Microbiol. Biotechnol. 14, 635-647. doi: 10.1023/A:1008848401799

Ternan, N. G., and Quinn, J. P. (1998). Phosphate starvation-independent 2-aminoethylphosphonic acid biodegradation in a newly isolated strain of Pseudomonas putida, NG2. Syst. Appl. Microbiol. 21, 346-352. doi: $10.1016 / S 0723-2020(98) 80043-\mathrm{X}$
Tilbrook, B. D., and Karl, D. M. (1995). Methane sources, distributions and sinks from California coastal waters to the oligotrophic North Pacific gyre. Mar. Chem. 49, 51-64. doi: 10.1016/0304-4203(94)00058-L

Uehara, T., Parzych, K. R., Dinh, T., and Bernhardt, T. G. (2010). Daughter cell separation is controlled by cytokinetic ring-activated cell wall hydrolysis. $E M B O$ J. 29, 1412-1422. doi: 10.1038/emboj.2010.36

Waltermann, M., and Steinbuchel, A. (2005). Neutral lipid bodies in prokaryotes: recent insights into structure, formation, and relationship to eukaryotic lipid depots. J. Bacteriol. 187, 3607-3619. doi: 10.1128/JB.187.11.3607-3619.2005

Wanner, B. L. (1993). Gene regulation by phosphate in enteric bacteria. J. Cell. Biochem. 51, 47-54. doi: 10.1002/jcb.240510110

Wanner, B. L., and Metcalf, W. W. (1992). Molecular genetic studies of a 10.9-kb operon in Escherichia coli for phosphonate uptake and biodegradation. FEMS Microbiol. Lett. 79, 133-139.

White, A. E., Karl, D. M., Björkman, K., Beversdorf, L. J., and Letelier, R. M. (2010). Production of organic matter by Trichodesmium IMS101 as a function of phosphorus source. Limnol. Oceanogr. 55, 1755-1767. doi: 10.4319/lo.2010.55.4.1755

White, A. K., and Metcalf, W. W. (2007). Microbial metabolism of reduced phosphorus compounds. Аnnu. Rev. Microbiol. 61, 379-400. doi: 10.1146/annurev.micro.61.080706.093357

Wu, J., Sunda, W., Boyle, E. A., and Karl, D. M. (2000). Phosphate depletion in the western North Atlantic Ocean. Science 289, 759-762. doi: 10.1126/science.289.5480.759

Yakovleva, G. M., Kim, S. K., and Wanner, B. L. (1998). Phosphate-independent expression of the carbon-phosphorus lyase activity of Escherichia coli. Appl. Microbiol. Biotechnol. 49, 573-578. doi: 10.1007/s002530051215

Zhang, Q., and Van Der Donk, W. A. (2012). Answers to the carbonphosphorus lyase conundrum. ChemBioChem 13, 627-629. doi: 10.1002/cbic. 201200020

Zinser, E. R., Lindell, D., Johnson, Z. I., Futschik, M. E., Steglich, C., Coleman, M. L., et al. (2009). Choreography of the transcriptome, photophysiology, and cell cycle of a minimal photoautotroph, Prochlorococcus. PLoS ONE 4:e5135. doi: 10.1371/journal.pone.0005135

Conflict of Interest Statement: The authors declare that the research was conducted in the absence of any commercial or financial relationships that could be construed as a potential conflict of interest.

Received: 28 August 2013; paper pending published: 13 September 2013; accepted: 29 October 2013; published online: 26 November 2013.

Citation: Martinez A, Ventouras L-A, Wilson ST, Karl DM and DeLong EF (2013) Metatranscriptomic and functional metagenomic analysis of methylphosphonate utilization by marine bacteria. Front. Microbiol. 4:340. doi: 10.3389/fmicb.2013.00340

This article was submitted to Aquatic Microbiology, a section of the journal Frontiers in Microbiology.

Copyright (๑) 2013 Martínez, Ventouras, Wilson, Karl and DeLong. This is an openaccess article distributed under the terms of the Creative Commons Attribution License (CC BY). The use, distribution or reproduction in other forums is permitted, provided the original author(s) or licensor are credited and that the original publication in this journal is cited, in accordance with accepted academic practice. No use, distribution or reproduction is permitted which does not comply with these terms. 